\title{
Expanding anchored hybrid enrichment to resolve both deep and shallow relationships within the spider tree of life
}

\author{
Chris A. Hamilton ${ }^{1 *+}$, Alan R. Lemmon ${ }^{2 \dagger}$, Emily Moriarty Lemmon ${ }^{3}$ and Jason E. Bond
}

\begin{abstract}
Background: Despite considerable effort, progress in spider molecular systematics has lagged behind many other comparable arthropod groups, thereby hindering family-level resolution, classification, and testing of important macroevolutionary hypotheses. Recently, alternative targeted sequence capture techniques have provided molecular systematics a powerful tool for resolving relationships across the Tree of Life. One of these approaches, Anchored Hybrid Enrichment (AHE), is designed to recover hundreds of unique orthologous loci from across the genome, for resolving both shallow and deep-scale evolutionary relationships within non-model systems. Herein we present a modification of the AHE approach that expands its use for application in spiders, with a particular emphasis on the infraorder Mygalomorphae.

Results: Our aim was to design a set of probes that effectively capture loci informative at a diversity of phylogenetic timescales. Following identification of putative arthropod-wide loci, we utilized homologous transcriptome sequences from 17 species across all spiders to identify exon boundaries. Conserved regions with variable flanking regions were then sought across the tick genome, three published araneomorph spider genomes, and raw genomic reads of two mygalomorph taxa. Following development of the 585 target loci in the Spider Probe Kit, we applied AHE across three taxonomic depths to evaluate performance: deep-level spider family relationships (33 taxa, 327 loci); family and generic relationships within the mygalomorph family Euctenizidae (25 taxa, 403 loci); and species relationships in the North American tarantula genus Aphonopelma (83 taxa, 581 loci). At the deepest level, all three major spider lineages (the Mesothelae, Mygalomorphae, and Araneomorphae) were supported with high bootstrap support. Strong support was also found throughout the Euctenizidae, including generic relationships within the family and species relationships within the genus Aptostichus. As in the Euctenizidae, virtually identical topologies were inferred with high support throughout Aphonopelma.

Conclusions: The Spider Probe Kit, the first implementation of AHE methodology in Class Arachnida, holds great promise for gathering the types and quantities of molecular data needed to accelerate an understanding of the spider Tree of Life by providing a mechanism whereby different researchers can confidently and effectively use the same loci for independent projects, yet allowing synthesis of data across independent research groups.
\end{abstract}

Keywords: Anchored Hybrid Enrichment, Anchored phylogenomics, Targeted sequence capture, Conserved regions, Ultraconserved elements, Araneae, Mygalomorphae, Arachnida

\footnotetext{
* Correspondence: chris@8legs2fangs.com

${ }^{\dagger}$ Equal contributors

${ }^{1}$ Department of Biological Sciences, Auburn University \& Auburn University

Museum of Natural History, Auburn, AL, USA

Full list of author information is available at the end of the article
} 


\section{Background}

Spiders (Order Araneae) constitute a diverse radiation of generalist predatory arthropods with over 45,000 nominal species [1] placed among 3,977 genera and 114 families; some estimates suggest the group may comprise as many as 120,000 species [2]. Diversifying since the Devonian (over 380 million years ago) [3, 4], this ancient group plays a dominant predatory role in almost every terrestrial ecosystem. In addition to their remarkable ecological importance, diversity, and abundance, spiders are known for their extraordinary biomolecules like venoms and silks, and have become models for behavioral and evolutionary studies (see reviews in [1, 5]).

The consensus view of spider phylogeny, summarized by Coddington and Levi [6] and Coddington [7], has changed relatively little over the past decade. The Order Araneae is divided into two suborders, the Mesothelae and Opisthothelae. The Mesothelae have a number of unique features including medially positioned spinnerets on the venter of the abdomen, vestiges of the abdominal segmentation common to more ancestral arachnid orders (e.g., scorpions), and are limited to one family (Liphistiidae) found only in Southeast Asia. The Opisthothelae comprises the infraorders Mygalomorphae and Araneomorphae. Mygalomorphae (e.g., trapdoor spiders, tarantulas, funnel web spiders and their relatives) is less diverse nominally ( $\sim 6 \%$ of the total number of described species) and has retained a number of features considered plesiomorphic among spiders (two pairs of book lungs, production of few, and biomechanically weak, silk types). Within the Araneomorphae (e.g., jumping spiders, wolf spiders, orb-weaving spiders, etc.), the monophyly of the major Haplogynae and Entelegynae clades is weakly to moderately supported on the basis of relatively few morphological features. The Haplogynae all lack a sclerotized epigyne (external female genitalic structure) and their monophyly is weakly based on characters from the chelicerae, palp, and spinnerets. Entelegynes typically possess a more complex reproductive system (a sclerotized epigyne with external copulatory openings), and comprise the vast majority of diversity in spiders. The entelegynes consist of multiple hyperdiverse groups (see [4]), including the Retrolateral Tibial Apophysis (RTA) clade (males possessing a unique morphological character on the palp - nearly half of all described spider taxa); the Dionychans (e.g., wolf, fishing, and jumping spiders) [8]; and the Orbiculariae (the lineage that contains most orb weaving spiders and their relatives) [9].

Despite considerable effort, progress in spider molecular systematics has lagged behind the advances made in other comparable arthropod groups. Unfortunately, this has hindered family-level resolution, classification, and tests of important macroevolutionary hypotheses (e.g., the origin of sticky silks, various web types and hunting strategies). Until recently, only 15 markers (13 of which are independent) had previously been used in spiders for phylogeny inference, very few of which are effective at the species level (Additional file 1: Table S1; for examples of loci and how they were used, see [10-18]). A major problem with the traditional markers is that they have often produced misleading or contradictory results [2]. The poor resolution often seen in traditional markers indicate it will take more than a handful of the "usual suspect" loci (markers that easily amplify and sequence, regardless of their phylogenetic information) [89] to overcome the stochasticity of sequence evolution and incongruence across spider gene trees.

\section{Phylogenomics}

Phylogenomic datasets, enabled by high-throughput sequencing, are transforming systematic biology by allowing researchers to confidently resolve many branches on the Tree of Life (TOL) [19] via the ability to gather vast quantities of genomic data with relative ease. Very recently, phylogenomic analyses based on transcriptome data (e.g., 3, 4) have for the first time been applied to deeper-level spider relationships. These studies clearly indicate relationships among spider families require a major overhaul (e.g., the non-monophyly of orb weavers). The use of hundreds and even thousands of loci identify the non-monophyly of the Orbiculariae and suggest that the orb web is likely plesiomorphic for entelygyne spiders [3]. Subsequently corroborated by Garrison et al. [4], this more recent study also calls into question the placement of the key haplogyne family Leptonetidae, as well as resolution among a number of the RTA clade families, and identifies areas on the phylogeny where putative bursts of diversification have occurred.

Although the use of transcriptome sequencing for phylogenetics has greatly advanced our understanding of relationships, by resolving deeper-level relationships of spiders [4], the generally conserved nature of transcribed protein-coding genes can have limited utility for resolving relationships towards the tips of the Tree of Life. Additionally, RNAseq sample prep and sequencing remains comparatively costly, both financially and in terms of feasibility (i.e., collection and storage - eliminating the ability to obtain samples from natural history collections). Transcriptome data are also dependent on expression patterns of the tissue sampled, can have potential issues with contamination and paralogy, and importantly, large amounts of missing data can be associated with transcriptome sequencing following quality control and assembly as taxon specific loci drop out during the loci filtering process (see [3]). Several recent papers call attention to the negative impact of missing data seen in large phylogenomic (transcriptome-based) datasets [20-23]. Moreover, 
conflicting phylogenetic signal has also been observed when transcriptome and targeted sequence capture data sets are compared see [24]. Unfortunately, it can be difficult to determine which phylogeny (transcriptome or targeted sequence capture) represents the true evolutionary history of the organisms under investigation. At this time, we simply do not have enough information (i.e., taxon sampling, or an understanding of genome evolution and the true selective pressures underlying the loci used in these analyses). We do know that one potential reason for this conflict is that recombination could be occurring in the loci sequenced from transcriptome data $[25,26]$, especially in genes with exons separated by long introns, a known issue in spiders (i.e., spider genomes are large with short exons and long introns, reminiscent of mammalian genomes; [27]). When adjacent sites in an alignment reside large distances from each other in the genome, gene tree discordance contributes phylogenetic noise ([28], but see [29]). While phylogenetic inference can be misled by recombination for any nuclear loci, whether obtained through AHE or transcriptomes, it is a particular danger for the types of loci frequently recovered in transcriptome sequencing, and one we attempt to address through the use of Anchored Hybrid Enrichment.

Lemmon et al.'s [30] targeted sequence capture or targeted hybrid enrichment (Anchored Hybrid Enrichment), Faircloth et al.'s [31] highly conserved regions (Ultraconserved Elements), and Li et al.'s [32] proteincoding genes, present alternative targeted sequencing approaches that focus on discovering and utilizing conserved regions throughout the genome. These significant changes in the loci available for phylogenetic inference provide a powerful approach for resolving both deep and shallow relationships across the animal TOL. Rather than sequencing only the expressed portions of a genome, hundreds or thousands of a priori loci, deemed putatively phylogenetically-informative, are targeted from across the genome to recover these conserved regions along with their flanking regions, using massively parallel high-throughput sequencing. Whereas the efficacy of these approaches has been demonstrated for vertebrate taxa $[24,30,33-41]$, the vast majority of invertebrate taxa lack reference genomes and contain considerable variation in genome size and complexity. For example, spiders exhibit large differences in chromosome number and genome size between and even within families [27, 42], an issue that has slowed the development of genomic resources. Our modified approach (described below) builds upon this previous vertebrate work, but makes available high-throughput targeted sequencing to nonmodel organisms and groups that lack fully assembled, annotated genomes.

\section{Anchored Hybrid Enrichment in spiders}

Anchored Hybrid Enrichment (AHE) [30] is a relatively new DNA sequencing methodology designed to recover hundreds of unique orthologous loci (i.e., single copy, phylogenetically-informative markers) from across the genome, for resolving both shallow and deep-scale evolutionary relationships within non-model systems. In its first incarnation, assembled, annotated vertebrate genomes were employed to build a scaffold from which probes were designed in conserved anchor regions neighboring variable flanking regions spread throughout the genome, creating a diverse set of probes that include exons, introns, intergenic, and conserved regions of the genome (see [19]). Anchored Hybrid Enrichment aims to increase phylogenetic power by providing access to datasets that allow for the sampling of more loci than what is currently available for most taxonomic groups, allow for an increase in number of taxa sampled (via multiplexing), and include loci informative at varying evolutionary time scales. Multiple factors make AHE an attractive and useful approach for systematists, including, but not limited to: its efficiency in non-model species, the high phylogenetically-informative content of the loci across shallow to deep taxonomic scales, the potentially low levels of missing data, rapid data collection, and cost effectiveness (see [19]).

By generating a genomic dataset that is one order of magnitude larger than those produced by traditional methods, we demonstrate that AHE provides a highthroughput sequencing approach that can be used to answer longstanding questions regarding the relationships and diversification of major spider groups, thereby providing the phylogenetic framework for addressing important evolutionary questions (e.g., the evolution of silk use and the evolution of spinning structures like the cribellum). As proof of concept, we apply AHE across three taxonomic depths within the Spider TOL to infer highly supported phylogenies: deep-level family relationships, with a particular emphasis on the infraorder Mygalomorphae (33 taxa); family and intergeneric relationships spanning the mygalomorph family Euctenizidae (25 taxa); and finally, species-level relationships in the North American tarantula genus Aphonopelma (83 taxa).

\section{Methods}

We present a modification of Lemmon et al. [30] that expands AHE for species lacking reference genomes. As described in Lemmon et al. (30; pg. 741), "Fully assembled genomes are not necessarily required for this effort; because probe regions were chosen based on conservation and uniqueness, low-coverage genome sequencing could potentially provide enough reads overlapping with probe regions to facilitate inclusion of underrepresented groups in the probe design." With this in mind, our aim 
was to design a set of probes to capture loci that are informative at a diversity of timescales across the evolutionary history of spiders.

Following the original AHE paper [30], a target of $\sim 500$ loci was chosen because simulation studies suggest the number of loci needed to resolve a phylogeny can range from tens to hundreds depending on the phylogenetic content of the loci (e.g., population size, and time between speciation events) [43-45]. A dataset of this size should be sufficient to resolve difficult nodes (e.g., short branch lengths relative to population size), as in the case of rapid radiations and recent divergences, while also accounting for deep coalescence, incomplete lineage sorting, and/or hybridization [44-48]. We focused on producing a set of markers that balanced the number of loci to be sequenced per individual, with the need for high sequencing coverage per sample, while at the same time efficiently capturing the anchor and flanking regions needed for informative sequence variation.

\section{Probe design}

Hybrid enrichment involves hybridizing short probe sequences to genomic DNA with subsequent enrichment of those regions of interest prior to sequencing. This approach allows the target loci to be separated from non-target regions of the genome [30]. Because capture efficiency is dependent on the similarity between probe and target, and because our aim was to use the same probe set across a very old taxonomic group, we maximized the chance of success by targeting conserved regions across spider genomic data using long, $120 \mathrm{bp}$ capture probes, with dense tiling. One of the advantages of this approach is that loci present across deep taxonomic groups (e.g., Arthropods) can be targeted using the same approach (e.g., hybrid enrichment), yielding datasets that can later be combined across studies. Because enrichment efficiency depends strongly on the level of sequence divergence between the probe and target sequences, however, an ideal kit will utilize probes derived from sequences that are both taken from the clade of interest and also represent the sequence diversity across the clade. This anchored phylogenomic approach, in which probes representing the diversity of the clade are used in probe design, allows one to target more variable probe regions with higher efficiency. From our experience, the tradeoff between utility and efficiency is optimized when target loci are identified at the level of phylum (or lower); probe kits are then developed for each order, with represented lineages being separated by no more than 200 million years (depending on the level of conservation of the targets).

One additional aspect of hybrid enrichment worth noting is that the robustness of the process to sequence divergence between the target species and the probes allows one to obtain all homologs of the target locus that have at least a moderate level of similarity to the target sequences (e.g. $70 \%$ ). This is advantageous for three reasons. First, it helps to ameliorate potential errors in identifying orthology during the probe design process. Second, it allows for one to obtain both copies resulting from unexpected gene duplications occurring in lineages not used to develop the probe set. Lastly, it allows one to collect data efficiently in clades with few or no single copy genes. For example, AHE has recently been used to target a comprehensive set of duplicated genes in Teleosts (Vertebrata, Actinopterygii, Teleostei), which have experienced two whole-genome duplications followed by loss of different genes in different lineages (Stout et al. in press).

We utilize as a starting point a published set of orthologous loci identified using a diverse set of insect taxa. Next, we identify putative arthropod-wide loci by searching for these loci in Arachnids, and then develop an Araneae-specific kit for efficient capture in spiders. More specifically, we began with nucleotide alignments of 4485 1:1 orthologs identified using OrthoMCL by Niehuis et al. $([49,50]$; Supplementary_file_archive_09.tgz) that contain 13 insects: 11 members of Holometabola from five orders (Diptera, Hymenoptera, Lepidoptera, Strepsiptera, and Coleoptera) and 2 non-holometabolous insects from 2 orders (Phthiraptera and Hemiptera). A full list of the species and their higher taxonomy is given in Table A of Additional file 2: Table S2. We then identified for each of the 13 species, corresponding sequences in the 1,478 transcriptome-based 1:1 orthologs identified by Misof et al. [51] using OrthoDB 5. After identifying the loci overlapping between the Niehuis and Misof studies, we selected a preliminary set of target loci by retaining only those Niehuis $[49,50]$ alignments containing $\geq 6$ taxa and at least one consecutive 120 bp region with $>50 \%$ pairwise sequence identity. Sequences for each species were then extracted and saved in separate fasta files (one per species). Exon boundaries were then identified using published genomes and custom scripts that identified matches between the transcript sequences and the genomes using 40-mers (scripts available in our Dryad supplemental materials, doi:10.5061/dryad.5027d) [90].

Together with the alignments, the exon boundaries were used to identify suitable candidate regions (exons) to target using an anchored phylogenomics approach, as described by Lemmon et al. [30]. The following requirements were used to select the 962 preliminary targets: A) the region was at least $150 \mathrm{bp}$ in length; B) the region contained no exon boundaries; and $\mathrm{C}$ ) the region contained no indel gaps. Details of these targets are given in Table B of Additional file 2: Table S2; alignments can be found in our Dryad supplemental materials [90]. The lengths of these targets ranged from $150 \mathrm{nt}$ to $863 \mathrm{nt}$ (mean $=187 \mathrm{nt}$ ), 
whereas the pairwise sequences similarity ranged from $45 \%$ to $84 \%$ (mean $=66 \%$ ).

We scanned the preliminary targets for homologous sequences in transcriptomes from 17 species across all spiders (though heavily biased towards the Mygalomorphae), and the tick Ixodes genome (Ixodida, Ixodidae) (Additional file 2: Table S2, Table C), using three divergent insects as references: Tribolium (Order Coleoptera), Mengenilla (Order Strepsiptera), and Bombyx (Order Lepidoptera). Then, for each locus, we used MAFFT (v7.023b with -genafpair and -maxiterate 1000 flags; [52]) to construct an alignment containing the best matching transcript from each of the 18 species (with $55 \%$ match minimum). Loci not containing both Aliatypus and Aphonopelma (Araneae, Mygalomorphae) were not considered further. In order to ensure good lineage and transcript representation, we also removed loci for which more than 2 of the remaining species had transcript lengths less than $80 \%$ as long as the maximum length of the two representatives. This winnowing process resulted in 225 alignments, with an average length of 854 bases (total 192,333 bp per species).

In order to identify exon boundaries in the transcript alignments, $>15 \mathrm{x}$ coverage raw genomic reads were obtained for Aliatypus and Aphonopelma at the Translational Science Laboratory in the College of Medicine at Florida State University (see GenomeSequencingSummary.xlsx for details, Additional file 3: Table S3). Raw genomic reads from each species were mapped to the 225 transcript sequences from the corresponding species and exon boundaries were identified as positions at which reads mapping on each side had poor matches on the opposite side. This process yielded 592 exons.

In addition to transcriptome-based data, we incorporated three additional Araneae lineages for which assembled genomes were available from the i5k Genome Sequencing Initiative ([53]; https://www.hgsc.bcm.edu/arthropods): the black widow (Latrodectus hesperus; Lhes.scaffolds.fa; made available on website 12/06/2013), the common house spider (Parasteatoda tepidariorum; Ptep01282013.genome.fa; made available on website 03/ 26/2013), and the brown recluse spider (Loxosceles reclusa; Lrec.scaffolds.fa made available on website 01/29/ 2014). We scanned each genome using references derived from the 592 exon alignments described above, and extracted from the genomes the regions corresponding to each exon (trimmed to match exon boundaries). Note that the more recently published Stegodyphus and Acanthoscurria genomes [27] were not included in the development of the Spider Probe Kit due to their availability occurring only after the kit was designed.

Spiders possess large, highly repetitive genomes, which present special challenges because repetitive elements can reduce capture efficiency [54-56]. Spider genome sizes have been reported to range from an estimated $<1$ Gb to $\geq 11 \mathrm{~Gb}[27,57]$, and our own genomic sequencing of the mygalomorph genera Aliatypus and Aphonopelma estimates the genome sizes to be $2.5 \mathrm{~Gb}$ and $16 \mathrm{~Gb}$ respectively. With that in mind, we checked for highcopy regions (e.g., microsatellites and transposable elements) in the probe region sequences using the three genome-derived references as follows. First, a database was constructed for each species using all 15-mers found in the trimmed probe region alignments for that species. We also added to the database all 15-mers that were $1 \mathrm{bp}$ removed from the observed 15-mers. The three genomes were then exhaustively scanned for the presence of exact matches to these 15-mers, with matches tallied at the corresponding probe region alignment position. Alignment regions containing $>100,000$ counts in any of the three species were masked to prevent probe tiling across these regions. Probes of 120 bp were tiled uniformly at 4.0x tiling density (for each of the 21 reference species $=18$ transcriptomes +3 genomes). Scripts used for locus selection and design, alignments, final probe region sequences, and the final probe sequences are available as supplemental materials in Dryad [90]. As this process only produced 35,630 of the 57,700 available in an Agilent Sure-Select enrichment kit, we replicated the number of probes for short loci (see Ara1KeyWithReplicates.xlsx for details, Additional file 4: Table S4).

\section{Sampling for sequencing}

The newly developed AHE probe set was employed to evaluate efficacy at three taxonomic depths across the Spider TOL (see Table 1 for list of sequenced taxa). To investigate deep-level family relationships across Araneae, 33 taxa were selected including Liphistius (Mesothelae) and lineages throughout the Opisthothelae (both Mygalomorphae and Araneomorphae). The second taxonomic depth investigated intergeneric relationships across the mygalomorph family Euctenizidae, where 25 taxa were sequenced covering all genera, as well as species relationships within the genus Aptostichus. The Euctenizidae were rooted with the family Idiopidae, its putative sister lineage [17]. To examine the ability of the probe kit to resolve species-level relationships, we investigated a putative recent radiation into the United States by sequencing 77 individuals within the North American tarantula genus Aphonopelma. Provided there was enough material, two specimens of each CO1 (DNA barcode) species proposed in Hamilton et al. [58] were sequenced; samples encompassed the geographic and genetic breadth of each putative species, including "cryptic species". Unfortunately, at the time of sequencing, some of these CO1 species were singletons or lacked good nuclear DNA for sequencing (i.e., old specimens whose tissue was not well preserved for genomic sequencing), so only one 
Table 1 A list of taxa sequenced for this project, and their taxonomic groupings ( $\mathrm{A}=$ Araneae; $\mathrm{B}=$ Euctenizidae; $\mathrm{C}=$ Aphonopelma)

\begin{tabular}{|c|c|c|c|c|c|}
\hline Specimen & Family & Genus & Species epithet & Dataset & \\
\hline MY_2873 & Actinopodidae & Actinopus & sp. & A & a \\
\hline AUMS_4177 & Antrodiaetidae & Antrodiaetus & unicolor & A & \\
\hline AUMS_11407 & Araneidae & Verrucosa & sp. Guatemala & A & a \\
\hline AUMS_719 & Atypidae & Sphodros & sp. & A & \\
\hline AUMS_11401 & Barychelidae & Psalistops & sp. Panama & A & \\
\hline MY_2635 & Ctenizidae & Hebestatis & theventi & A & \\
\hline MY_565 & Ctenizidae & Stasimopus & $\mathrm{sp}$. & A & \\
\hline AUMS_4566 & Ctenizidae & Ummidia & sp. North Carolina & A & \\
\hline MY_515 & Cyrtaucheniidae & Ancylotrypa & sp. & A & \\
\hline MY_3399 & Cyrtaucheniidae & Fufius & sp. & A & \\
\hline MY_530 & Cyrtaucheniidae & Homostola & paradalina & A & \\
\hline AUMS_11400 & Dipluridae (?) & Linothele (?) & sp. Panama & A & \\
\hline MY_2485 & Euctenizidae & Apomastus & sp. & B & \\
\hline MY_2519 & Euctenizidae & Aptostichus & aguacaliente & B & \\
\hline MY_3630 & Euctenizidae & Aptostichus & angelinajolieae & B & \\
\hline MY_0741 & Euctenizidae & Aptostichus & atomarius & B & \\
\hline MY_3029 & Euctenizidae & Aptostichus & barackobamai & B & \\
\hline MY_2521 & Euctenizidae & Aptostichus & cahuilla & B & \\
\hline MY_0730 & Euctenizidae & Aptostichus & dantrippi & B & \\
\hline MY_2279 & Euctenizidae & Aptostichus & edwardabbeyi & B & \\
\hline MY_0265 & Euctenizidae & Aptostichus & hedinorum & B & \\
\hline MY_2496 & Euctenizidae & Aptostichus & hesperus & B & \\
\hline MY_2512 & Euctenizidae & Aptostichus & icenoglei & B & \\
\hline MY_3771 & Euctenizidae & Aptostichus & madera & B & \\
\hline MY_3524 & Euctenizidae & Aptostichus & miwok & B & \\
\hline MY_3081 & Euctenizidae & Aptostichus & simus & $A, B$ & \\
\hline AUMS_11458 & Euctenizidae & Aptostichus & sp. Baja - MX & B & a \\
\hline MY_3486 & Euctenizidae & Aptostichus & stanfordianus & B & \\
\hline MY_3492 & Euctenizidae & Aptostichus & stephencolberti & B & \\
\hline AUMS_11404 & Euctenizidae & Entychides & sp. Arizona & B & \\
\hline MY_3548 & Euctenizidae & Entychides & sp. Mexico & B & a \\
\hline EU_80 & Euctenizidae & Eucteniza & sp. & B & a \\
\hline AUMS_053 & Euctenizidae & Moss Landing gen. nov. & sp. & B & \\
\hline AUMS_081 & Euctenizidae & Myrmekiaphila & tigris & B & \\
\hline MY_272 & Euctenizidae & Neoapachella & sp. & B & \\
\hline MY_3688 & Euctenizidae & Promyrmekiaphila & sp. & B & \\
\hline MY_2049 & Hexathelidae & Atrax & sp. & A & \\
\hline MY_2045 & Hexathelidae & Bymainiella & sp. & A & \\
\hline AUMS_156 & Hypochilidae & Hypochilis & sp. & A & \\
\hline AUMS_6747 & Idiopidae & Idiops & sp. Namibia & $A, B$ & \\
\hline AUMS_5743 & Liphistiidae & Liphistius & sp. & A & \\
\hline AUMS_11467 & Lycosidae & Schizocosa & crassipes & A & \\
\hline AUMS_5112 & Lycosidae & Schizocosa & duplex & A & \\
\hline
\end{tabular}


Table 1 A list of taxa sequenced for this project, and their taxonomic groupings ( $A=$ Araneae; $B=$ Euctenizidae; $C=$ Aphonopelma) (Continued)

\begin{tabular}{|c|c|c|c|c|}
\hline AUMS_5615 & Lycosidae & Schizocosa & ocreata & A \\
\hline AUMS_5605 & Lycosidae & Schizocosa & rovneri & A \\
\hline salt-a & Lycosidae & Schizocosa & saltatrix & A \\
\hline AUMS_5604 & Lycosidae & Schizocosa & stridulans & A \\
\hline AUMS_0548 & Mecicobothriidae & Hexura & sp. & A \\
\hline MY_2138 & Migidae & Heteromigas & sp. & A \\
\hline MY_2096 & Nemesiidae & Chenistonia & sp. & A \\
\hline MY_2139 & Nemesiidae & Ixamatus & sp. & A \\
\hline MY_2094 & Nemesiidae & Kiama & sp. & A \\
\hline AUMS_6720 & Nemesiidae & Pionothele & sp. Namibia & A \\
\hline MY_2092 & Nemesiidae & Stanwellia & hoggi & A \\
\hline AUMS_6256 & Paratropididae & Paratropis & sp. Columbia & A \\
\hline APH_0856 & Theraphosidae & Aphonopelma & anax & C \\
\hline APH_3121 & Theraphosidae & Aphonopelma & anax & C \\
\hline APH_0871 & Theraphosidae & Aphonopelma & anax & C \\
\hline APH_0889 & Theraphosidae & Aphonopelma & anax & C \\
\hline APH_0554 & Theraphosidae & Aphonopelma & armada & C \\
\hline APH_0922 & Theraphosidae & Aphonopelma & armada & C \\
\hline APH_1478 & Theraphosidae & Aphonopelma & atomicum & C \\
\hline APH_1479 & Theraphosidae & Aphonopelma & atomicum & C \\
\hline APH_3001 & Theraphosidae & Aphonopelma & belindae & C \\
\hline APH_1438 & Theraphosidae & Aphonopelma & catalina & C \\
\hline APH_1602 & Theraphosidae & Aphonopelma & catalina & C \\
\hline APH_0174 & Theraphosidae & Aphonopelma & chalcodes & C \\
\hline APH_0954 & Theraphosidae & Aphonopelma & chalcodes & C \\
\hline APH_1003 & Theraphosidae & Aphonopelma & chalcodes & C \\
\hline APH_0049 & Theraphosidae & Aphonopelma & chalcodes & C \\
\hline APH_3128 & Theraphosidae & Aphonopelma & chalcodes & C \\
\hline APH_3191 & Theraphosidae & Aphonopelma & chiricahua & C \\
\hline APH_1009 & Theraphosidae & Aphonopelma & eutylenum & C \\
\hline APH_3143 & Theraphosidae & Aphonopelma & eutylenum & C \\
\hline APH_0850 & Theraphosidae & Aphonopelma & gabeli & C \\
\hline APH_3126 & Theraphosidae & Aphonopelma & gabeli & C \\
\hline APH_0645 & Theraphosidae & Aphonopelma & hentzi & $A, C$ \\
\hline APH_0934 & Theraphosidae & Aphonopelma & hentzi & C \\
\hline APH_1063 & Theraphosidae & Aphonopelma & hentzi & C \\
\hline APH_0586 & Theraphosidae & Aphonopelma & hentzi & C \\
\hline APH_3118 & Theraphosidae & Aphonopelma & icenoglei & C \\
\hline APH_0756 & Theraphosidae & Aphonopelma & icenoglei & C \\
\hline APH_2000 & Theraphosidae & Aphonopelma & iodius & C \\
\hline APH_2029 & Theraphosidae & Aphonopelma & iodius & C \\
\hline APH_2016 & Theraphosidae & Aphonopelma & iodius & C \\
\hline APH_0006 & Theraphosidae & Aphonopelma & iodius & C \\
\hline
\end{tabular}


Table 1 A list of taxa sequenced for this project, and their taxonomic groupings ( $A=$ Araneae; $B=$ Euctenizidae; $C=$ Aphonopelma) (Continued)

\begin{tabular}{|c|c|c|c|c|c|}
\hline APH_2020 & Theraphosidae & Aphonopelma & iodius & $C$ & \\
\hline APH_3103 & Theraphosidae & Aphonopelma & iodius & C & \\
\hline APH_1075 & Theraphosidae & Aphonopelma & iodius & C & \\
\hline APH_1078 & Theraphosidae & Aphonopelma & iodius & C & \\
\hline APH_2013 & Theraphosidae & Aphonopelma & iodius & C & \\
\hline APH_0997 & Theraphosidae & Aphonopelma & iodius & C & \\
\hline APH_1004 & Theraphosidae & Aphonopelma & iodius & C & \\
\hline APH_2032 & Theraphosidae & Aphonopelma & johnnycashi & C & \\
\hline APH_2008 & Theraphosidae & Aphonopelma & johnnycashi & C & \\
\hline APH_3094 & Theraphosidae & Aphonopelma & johnnycashi & C & \\
\hline APH_1007 & Theraphosidae & Aphonopelma & joshua & C & \\
\hline APH_1498 & Theraphosidae & Aphonopelma & joshua & C & \\
\hline APH_3177 & Theraphosidae & Aphonopelma & madera & C & \\
\hline APH_0136 & Theraphosidae & Aphonopelma & madera & C & \\
\hline APH_1618 & Theraphosidae & Aphonopelma & mareki & C & \\
\hline APH_3161 & Theraphosidae & Aphonopelma & mareki & C & \\
\hline APH_0297 & Theraphosidae & Aphonopelma & mareki & C & \\
\hline APH_0772 & Theraphosidae & Aphonopelma & marxi & C & \\
\hline APH_1535 & Theraphosidae & Aphonopelma & marxi & C & \\
\hline APH_0890 & Theraphosidae & Aphonopelma & moderatum & C & \\
\hline APH_0930 & Theraphosidae & Aphonopelma & moderatum & C & \\
\hline APH_0892 & Theraphosidae & Aphonopelma & moderatum & C & \\
\hline APH_0894 & Theraphosidae & Aphonopelma & moderatum & C & \\
\hline APH_0948 & Theraphosidae & Aphonopelma & moellendorfi & C & ${ }^{a}$ \\
\hline APH_0754 & Theraphosidae & Aphonopelma & mojave & C & \\
\hline APH_3101 & Theraphosidae & Aphonopelma & mojave & C & \\
\hline APH_3166 & Theraphosidae & Aphonopelma & paloma & C & \\
\hline APH_3190 & Theraphosidae & Aphonopelma & paloma & C & \\
\hline APH_3178 & Theraphosidae & Aphonopelma & parvum & C & \\
\hline APH_3187 & Theraphosidae & Aphonopelma & parvum & C & \\
\hline APH_0683 & Theraphosidae & Aphonopelma & peloncillo & C & \\
\hline APH_0723 & Theraphosidae & Aphonopelma & peloncillo & C & \\
\hline APH_0350 & Theraphosidae & Aphonopelma & prenticei & C & \\
\hline APH_0352 & Theraphosidae & Aphonopelma & prenticei & C & \\
\hline APH_3176 & Theraphosidae & Aphonopelma & saguaro & C & \\
\hline APH_0622 & Theraphosidae & Aphonopelma & sp. nov. 1 & C & \\
\hline APH_0880 & Theraphosidae & Aphonopelma & sp. nov. 2 & C & \\
\hline APH_3012 & Theraphosidae & Aphonopelma & sp. burica & C & \\
\hline APH_1023 & Theraphosidae & Aphonopelma & steindachneri & C & \\
\hline APH_3096 & Theraphosidae & Aphonopelma & steindachneri & C & \\
\hline APH_1443 & Theraphosidae & Aphonopelma & superstitionense & C & \\
\hline APH_0185 & Theraphosidae & Aphonopelma & vorhiesi & C & \\
\hline APH_0186 & Theraphosidae & Aphonopelma & vorhiesi & C & \\
\hline
\end{tabular}


Table 1 A list of taxa sequenced for this project, and their taxonomic groupings ( $\mathrm{A}=$ Araneae; $\mathrm{B}=$ Euctenizidae; $\mathrm{C}=$ Aphonopelma) (Continued)

\begin{tabular}{|c|c|c|c|c|}
\hline$\overline{\mathrm{APH} \_0717}$ & Theraphosidae & Aphonopelma & vorhiesi & $\mathrm{C}$ \\
\hline APH_0674 & Theraphosidae & Aphonopelma & vorhiesi & C \\
\hline APH_3188 & Theraphosidae & Aphonopelma & vorhiesi & C \\
\hline APH_3132 & Theraphosidae & Aphonopelma & xwalxwal & C \\
\hline APH_3134 & Theraphosidae & Aphonopelma & xwalxwal & C \\
\hline APH_3056 & Theraphosidae & Cyrtopholis & portoricae & C \\
\hline APH_3004 & Theraphosidae & Sericopelma & sp. Panama & C \\
\hline AUMS_10968 & Theraphosidae & Stichoplastoris & sp. Costa Rica & C \\
\hline APH_3021 & Theraphosidae & unknown genus & sp. Mexico dwarf & C \\
\hline
\end{tabular}

adenotes a tissue as "old" (see text for explanation)

specimen represented that species. Six additional specimens of Central American and Caribbean genera (i.e., Aphonopelma, Cyrtopholis, Sericopelma, Stichoplastoris, and an unknown putative novel genus from Mexico) were included to test the monophyly of the North American Aphonopelma. Furthermore, to evaluate the utility of AHE sequencing on specimens in natural history collections, we extracted and sequenced six specimens in differing states of preservation. Specimens that were designated as old tissue (see Table 1) included taxa that were either $\geq 10$ years old and stored in $\geq 95 \%$ $\mathrm{EtOH}$ in a $-20{ }^{\circ} \mathrm{C}$ freezer (AUMS_11407, AUMS_11458, MY_2873), taxa $\geq 10$ years old and stored in $80 \% \mathrm{EtOH}$ on a shelf in the AUMNH collection (EU_80, MY_3548), or taxa collected $\leq 10$ years old, initially preserved in Isopropyl $\mathrm{EtOH}$, transferred to $\geq 95 \% \mathrm{EtOH}$ and stored in a $-80{ }^{\circ} \mathrm{C}$ freezer (APH_0948). High-quality genomic DNA $(\geq 1 \mu \mathrm{g})$ for all specimens was extracted using a Qiagen DNeasy Blood \& Tissue kit, drawn from leg tissue that had been preserved using RNAlater or $\geq 95 \% \mathrm{EtOH}$ and stored in a $-80{ }^{\circ} \mathrm{C}$ freezer within the AUMNH cryo-collection, or from the shelves of the AUMNH. DNA concentration was evaluated through agarose gel electrophoresis and spectrophotometry using a NanoDrop ND-1000.

\section{Library preparation, enrichment, and sequencing}

Anchored Hybrid Enrichment data were collected through the Center for Anchored Phylogenomics at Florida State University (www.anchoredphylogeny.com) following the general methods of Lemmon et al. [30] and Prum et al. [59]. Briefly, each genomic DNA sample was sonicated to a fragment size of $\sim 175-325$ bp using a Covaris E220 Focused-ultrasonicator with Covaris microTUBES. Subsequently, library preparation and indexing were performed on a Beckman-Coulter Biomek FXp liquid-handling robot following a protocol modified from Meyer and Kircher [60]. One important modification is a size-selection step after blunt-end repair using SPRIselect beads (Beckman-Coulter Inc.; 0.9x ratio of bead to sample volume). Indexed samples were then pooled at equal quantities (approximately 16 samples per pool), and enrichments were performed on each multi-sample pool using an Agilent Custom SureSelect kit (Agilent Technologies), described herein as the Spider Probe Kit, that contained the probes designed for AHE loci from the spider genomic data detailed above. After enrichment, each set of reactions were pooled in equal quantities for sequencing on three PE150 Illumina HiSeq2500 lanes. Sequencing was performed in the Translational Science Laboratory in the College of Medicine at Florida State University.

\section{Data processing}

Reads were filtered for quality using Illumina's Casava software with a high chastity filter. Read length and accuracy was improved by merging overlapping reads following Rokyta et al. [61]. This process also trimmed and removed adapters. Merged reads and non-overlapping read pairs were used downstream. All reads were assembled into contigs following Prum et al. [59], but using references derived from the Ixodes, Hypochilus, Aphonopelma, and Aliatypus sequences used for probe design. The assembler produces separate contigs for gene copies differing by more than $5 \%$ sequence divergence. To reduce errors caused by low-level indexing errors during sequencing, contigs were then filtered by removing those derived from fewer than 35 reads. Supplemental file P0073_AssemblySummary_Summary.xlsx (Additional file 5: Table S5) provides a summary of the sequence data collected and resulting assemblies. Figure 1 illustrates these assemblies, for each taxon group and specimen. Each point represents one consensus sequence, with the length (bp) on the $y$-axis and the sequences grouped by sample on the $\mathrm{x}$-axis. The majority of consensus sequences are shorter than $1000 \mathrm{bp}$, though there is a small group of loci per individual that are greater. The exceptionally long assemblies are due to messy ends (e.g. microsats) and are 


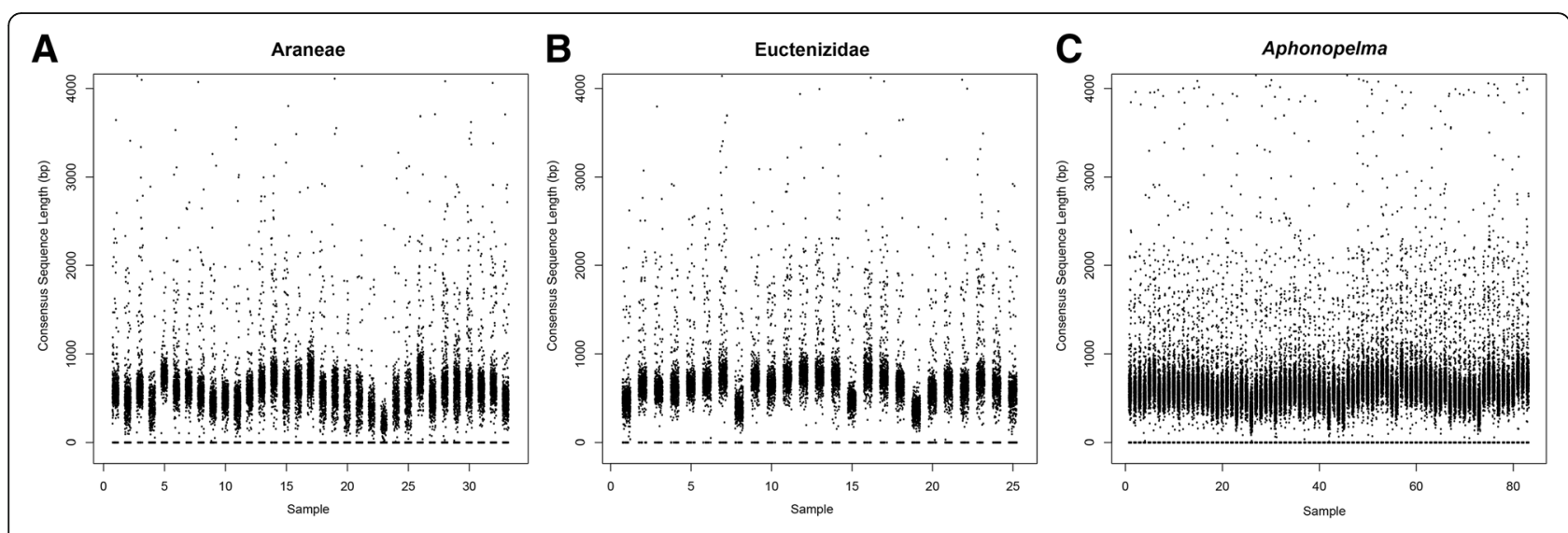

Fig. 1 Assemblies for each taxon group and specimen $(\mathbf{a}=$ Araneae, $\mathbf{b}=$ Euctenizidae, $\mathbf{c}=$ Aphonopelma $)$, used to produce the homologous sequence sets. Each point represents one consensus sequence, with the length (bp) on the $y$-axis and the sequences grouped by sample on the $x$-axis

discarded during the trimming steps. Due to thresholds designed to minimize missing data, the autotrimmer removes these jagged ends of the alignments when creating consensus sequences.

Homologous sequence sets were produced by grouping filtered consensus sequences across individuals by target locus. Orthologous groups were then determined for each target locus following Prum et al. [59]: A) a pairwise-distance measure was computed for pairs of homologs, with distance being computed as the percentage of 20-mers observed in the two sequences that were found in both sequences. In order to accommodate variable third codon positions in exonic regions, we included 20-mers comprised bases found every third position in addition to 20-mers from contiguous; B) a neighbor-joining clustering algorithm was then used to cluster the consensus sequences into orthologous sets, with at most one sequence per species in each orthologous set. The algorithm is as follows: A) compute pairwise 20-mer distance for all homologs as described above; B) identify the two homologous sequences from different individuals with the minimum distance; $C$ ) group the two identified sequences in a cluster; D) repeat steps A-C, treating each cluster as a sequence by using the average distance between the cluster and other clusters/sequence when assessing distance. For duplications occurring before the ancestor of the taxonomic group being analyzed, the method efficiently divides the homologs into two or more orthologous sets. For duplications occurring within the taxonomic group under investigation, the method tends to produce a single cluster containing one sequence per taxon and a second cluster containing sequences from those taxa that are descendants from the ancestor in which the duplication occurred. Cases in which orthology is difficult result in several clusters each containing a fraction of the taxa. In order to improve this situation and to minimize the effects of missing data, clusters containing fewer than (75\%) of the species were removed from downstream processing. This approach to orthology assessment is particularly well suited to data collected by AHE for two reasons. First it allows the utilization of noncoding sequences (e.g. flanks) that tend to be more variable and thus useful for identifying orthology at shallower taxonomic scales. Second it allows one to utilize taxa from remote portions of the Tree of Life that are underrepresented in databases such as OrthoDB [62].

Sequences in each orthologous set were aligned using MAFFT v7.023b [52] with -genafpair and -maxiterate 1000 flags. In order to remove poorly aligned regions, raw alignments were then trimmed and masked following Prum et al. [59], with the following adjustments: sites with $>70 \%$ similarity were identified as good, 20 bp regions containing $<10$ good sites were masked, and sites with fewer than 10 unmasked bases were removed from the alignment.

\section{Phylogenetic inference}

For each taxonomic dataset, a concatenated supermatrix of all loci was constructed to infer relationships using Maximum Likelihood (ML) phylogenetic inference in RAxML v8.1.9 [63, 64]. Because RAxML is limited in the choice of models of sequence evolution that can be chosen, we used the $(G T R+\Gamma)$ model. Based on evaluating the most appropriate model of sequence evolution on a subsample of the Spider Probe Kit loci using jModelTest v2.1.7 [65], the GTR $+\Gamma$ model was found to only slightly over-parameterize most loci. Parameters for the concatenated RAxML analyses were based on 1000 random addition sequence replicates (RAS), with branch 
support values computed via 1000 non-parametric bootstrap replicates, and partitions were set for each locus.

With the knowledge that a single gene tree almost certainly will not reflect the true evolutionary history of a lineage [66], we attempted to infer the species tree for each of our three taxonomic depth investigations. Modern species tree inference methods that jointly estimate gene trees and the species tree under the multispecies coalescent model (MSC) are unable to feasibly utilize phylogenomic datasets of this size (both computationally and temporally, e.g., "BEAST). Due to this limitation, we inferred phylogenies for each individual locus using RAxML, under the same guidelines as above with subsequent species tree estimation using ASTRAL II v4.7.8 [67], from all individual unrooted gene trees (and bootstrap replicates). ASTRAL, a gene-tree method based in coalescent theory, attempts to find the species tree that agrees with the largest number of quartet trees, from a set of gene trees, under a "quasi" multispecies coalescent approach. Quartet-based supertree methods combine many quartet trees into a single and coherent tree, over the complete set of taxa (see [68]). ASTRAL has been shown to be statistically consistent under the multispecies coalescent model, is thought to be a fast and accurate alternative to other "shortcut" or "two-step" coalescent methods like MP-EST [69], and importantly, ASTRAL performs consistently in the anomaly zone ([29, 70-72]; Warnow unpublished - see http://tandy.cs.illinois.edu). An advantage of inferring phylogenies from multiple loci is that if relationships consistently emerge across individual gene trees, confidence can be taken from this phylogenetic resolution.

Additionally, investigations into simulated and empirical datasets have shown that, if there is strong incongruence between loci, concatenated supermatrices are likely to return incorrect trees that are strongly supported [70, 71, 73]. For deep phylogenetic problems, the utility of a coalescence approach has been debated (see $[29,74,75])$. The idea that shortcut coalescence methods (e.g., STEM, STAR, and MP-EST) perform poorly when individual gene trees are inferred and subsequently used to sort deep coalescences among gene trees has been proposed by Gatesy and Springer [74]. Mirarab et al. [69] have shown that concatenation can be more accurate than phylogenetic inference under the multi-species coalescent, if low amounts of incomplete lineage sorting are present, yet under biologically realistic conditions, coalescent-based methods can be more accurate than concatenation [29], conflicting with Gatesy and Springer [74]. A potential explanation for this conflict and/or lack of resolution is that present phylogenetic methods cannot adequately model the complex processes of molecular evolution inherent in such large data sets (see [76]). Thus we feel it is important to analyze datasets, such as these herein, using both a combined supermatrix and species tree phylogenetic inference. An approach such as this provides opportunities to more thoroughly detect and investigate gene tree discordance or hidden signal throughout the dataset. Because of these fundamental differences, we chose to infer phylogenies using both the concatenated supermatrix and MSC approaches, and evaluate agreement or discordance between them. All investigations were carried out on the CASIC HPC at Auburn University and the FSU Center for Anchored Phylogenomics.

\section{Results \& discussion}

\section{Probe design \& sequencing}

The Spider AHE Probe Kit, comprises a total of 585 orthologous target loci chosen on the basis of conservation and uniqueness, capable of constituting a dataset with over 400,000 bp. Based on the divergence estimates reported in Bond et al. [3] and Garrison et al. [4], the taxa used as genomic models to develop the Spider Probe Kit encompass an estimated time span of $>300$ mya, the widest implementation of targeted hybrid enrichment to date. Following recovery and analysis, shorter loci correspond to genomic regions that are less variable and appear better at recovering deep to medium nodes, whereas longer loci are highly variable and work well for resolving more shallow nodes (in particular, species relationships). The length of the loci utilized in this analysis range from $101 \mathrm{bp}$ to $2146 \mathrm{bp}$, with parsimony informative characters (PICs) ranging from 1 to 794 per locus (Figs. 2 \& 3). The numbers of PICs across the taxonomic groupings are significantly correlated with length (bp) in all of the datasets (each $p<2 \mathrm{e}-16$; Araneae Adjusted Rsquared $=0.9575$, Euctenizidae Adjusted R-squared $=$ 0.7064, Aphonopelma Adjusted R-squared = 0.1179).

As seen in Lemmon et al. [30] and herein, a smaller number of loci are captured from deeper taxonomic depths, (e.g., the 581 loci in the Aphonopelma dataset decreases to 327 in the Araneae dataset; see Figs. 2 \& 3). The biological reality is that not all loci should be expected to capture, enrich, and sequence properly for all individuals; loci are lost due to a number of possibilities, including deep divergence between outgroup and ingroup, sequence change in the probe region, poor quality DNA, library preparation failure, poor quality of sequencing reads, and issues during assembly and orthology assessment. Though the number of captured orthologs shared across our sampled taxa decreases as evolutionary distances among the lineages increases, a decline in number of loci does not correspond with a loss in relative informativeness, as evidenced by robust support throughout our phylogenies. We now know a simple count of the numbers of loci used for phylogeny inference should not be compared to the numbers of 

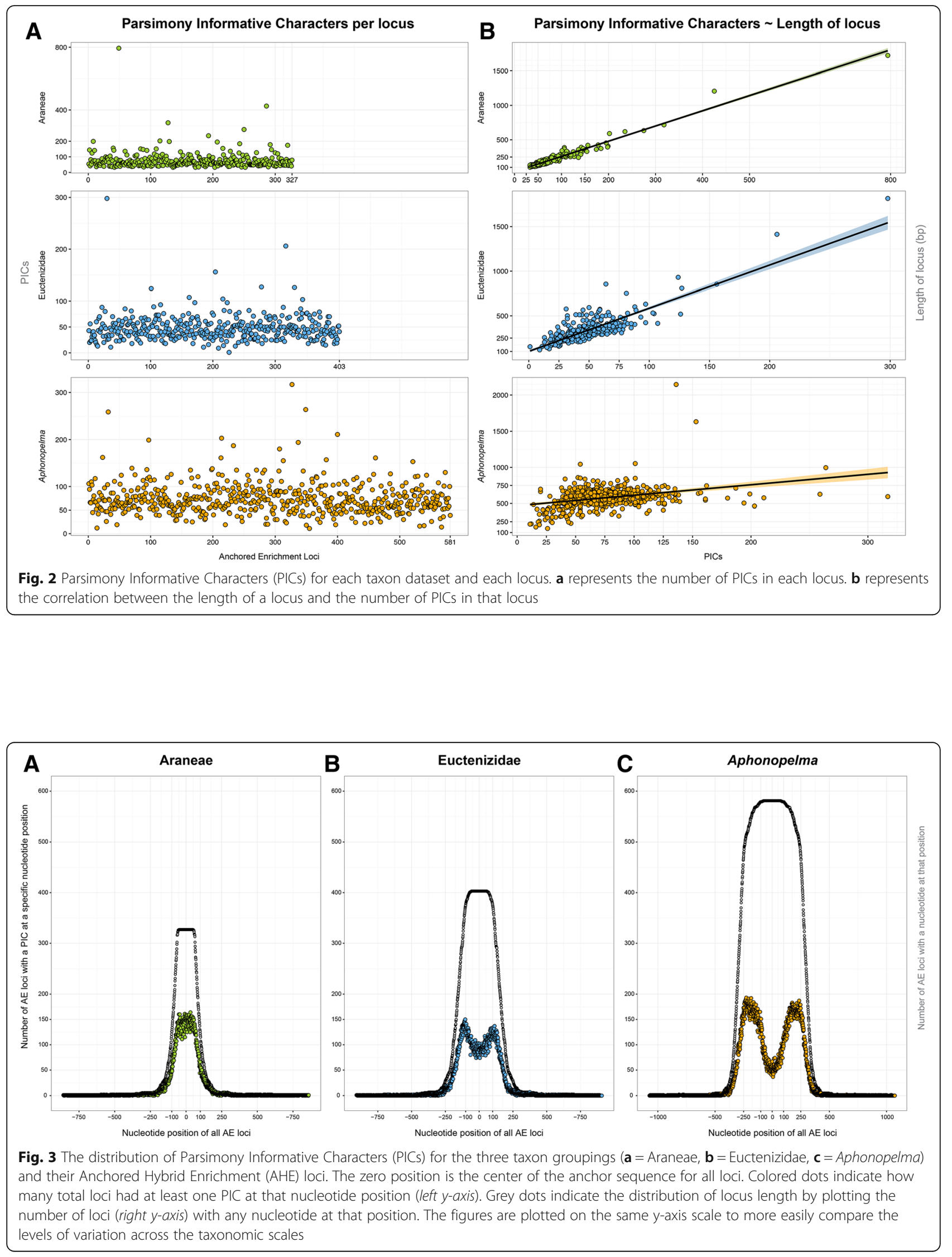
loci one can obtain from other sequencing approaches (e.g., UCEs or transcriptome data). The argument that the use of more loci in an analysis provides a better outcome is not necessarily the truest case for robust phylogeny inference; an ideal approach is to utilize a priori loci deemed phylogenetically-informative for the particular question [77]. Although the spider probe kit provides good enrichment efficiency (1\%-15\% of reads mapping to target loci), given the large genome size, deep taxonomic depth, and variable sample quality, an increased representation of Araneomorphae would increase the capture efficiency in that clade. Additional sequencing information (e.g., number of reads recovered for each sample) can be viewed in P0073_AssemblySummary_ Summary.xlsx (Additional file 5: Table S5). The Illumina sequencing reads and assembled sequences have been deposited in the Dryad data repository (http://datadryad.org, doi:10.5061/dryad.5027d).

\section{Order Araneae}

Following hybrid enrichment, sequencing, and implementation of the AHE bioinformatics pipeline (outlined above), a dataset of 327 loci comprising 67,870 bp for 33 OTUs was selected for phylogenetic inference and evaluation of the efficacy of this methodology to recover Araneae relationships. This dataset contains 30,340 variable sites, 25,871 informative sites, and $16 \%$ total missing characters. Of the 327 loci, an average of 29 taxa were represented in each locus. The length of the individual alignments ranged between $101 \mathrm{bp}$ and $1721 \mathrm{bp}$, with a mean of $207 \mathrm{bp}$, and the number of PICs per locus range from 33-794 (Figs. 2 \& 3a). Liphistius was used to root the phylogeny [3]. Analyses of the concatenated supermatrix and ASTRAL species tree estimation were largely congruent, with high bootstrap support among most nodes. The supermatrix phylogeny recovers all three major spider lineages with high bootstrap support, the Mesothelae, Mygalomorphae, and Araneomorphae. Due to phylogenetic methodology restrictions at this time (see $[29,69,74,75])$, our preference of the supermatrix inferred phylogeny is likely the more appropriate evaluation of the data at this timescale (Fig. 4a). Lineages with a different placement between the two outcomes are indicated in yellow on the phylogeny (Fig. 4b). Within this dataset, sampling is sparse among araneomorphs at this time, reflecting our initial emphasis on mygalomorph taxa - a relatively wellsampled Mygalomorphae clade consisting of 14 out of the 16 families (missing the Dipluridae and Microstigmatidae). Within the Araneomorphae, the Entelegynae clade is represented by the orb-weaver genus Verrucosa (Araneidae) and the wolf spider genus Schizocosa (Lycosidae). In both the supermatrix and ASTRAL analyses, the entelegyne clade is monophyletic and sister to the
Haplogynae (represented by Hypochilus). Additionally, species-level relationships within Schizocosa are highly supported (>95 bootstrap support (bs)).

Within the Mygalomorphae, sampling is not sufficient enough to allow for a direct comparison with the findings of Bond et al. [3], however major, long-hypothesized lineages such as the Atypoidea (Atypidae, Antrodiaetidae, and Mecicobothriidae), Avicularioidea (all other mygalomorph families), and Theraphosoidina are well supported in both inference approaches, (Figs. 2 and 3). There is high support for a number of nodes in both the supermatrix and species tree analyses. Importantly, these include: A) within the Avicularioidea, there is one highly supported, monophyletic clade consisting of Nemesiidae lineages (Stanwellia, Pionothele, Kiama, Chenistonia, and Ixamatus), the cyrtaucheniid genus Fufius, and a specimen from Panama that was intended as a representative of the family Dipluridae, identified morphologically as the genus Linothele, however its placement in the phylogeny clearly indicates that it is most likely a nemesiid; B) a sister group relationship between Actinopodidae (Actinopus) and the Hexathelidae genus Atrax; C) a monophyletic sister group relationship between the North American ctenizid genera Ummidia and Hebestatis); D) a highly supported, monophyletic Theraphosoidina that includes a monophyletic clade of the cyrtaucheniid genera Ancylotrypa and Homostola, sister to a monophyletic clade of Barychelidae (Psalistops) and Theraphosidae (Aphonopelma). Unfortunately, across both analyses there is a lack of resolution at the medium nodes within the Mygalomorphae. Though largely congruent between the two phylogenies, there is conflicting placement of the families Actinopodidae, Ctenizidae, Euctenizidae, Hexathelidae, Idiopidae, Migidae, and Paratropididae at those intermediate nodes. Significant disagreement occurs between the supermatrix and species tree analyses in the placement of the Paratropididae (Paratropis), the ctenizid genus Stasimopus, and the hexathelid Bymainiella. The supermatrix analysis indicates high support for the placement of Bymainiella (Hexathelidae) and Paratropis (Paratropididae) as the sister lineages to the vast majority of mygalomorph diversity, consistent with Bond et al. [3], whereas in the species tree paratropidids are the sister group to the clade that includes ctenizids, euctenizids, idiopids, and other taxa.

Important comparisons with Bond et al. [3] that continue to emphasize the problems in mygalomorph classification include: both analyses corroborate the elevation of euctenizines to the family level, though the sister group to Euctenizidae (supermatrix = Idiopidae, species tree $=$ Migidae) (Fig. 4) remains unresolved, without increased sampling; Actinopus and Atrax are robustly supported as sister, though their placement in the phylogeny differs greatly; and lastly, both analyses 


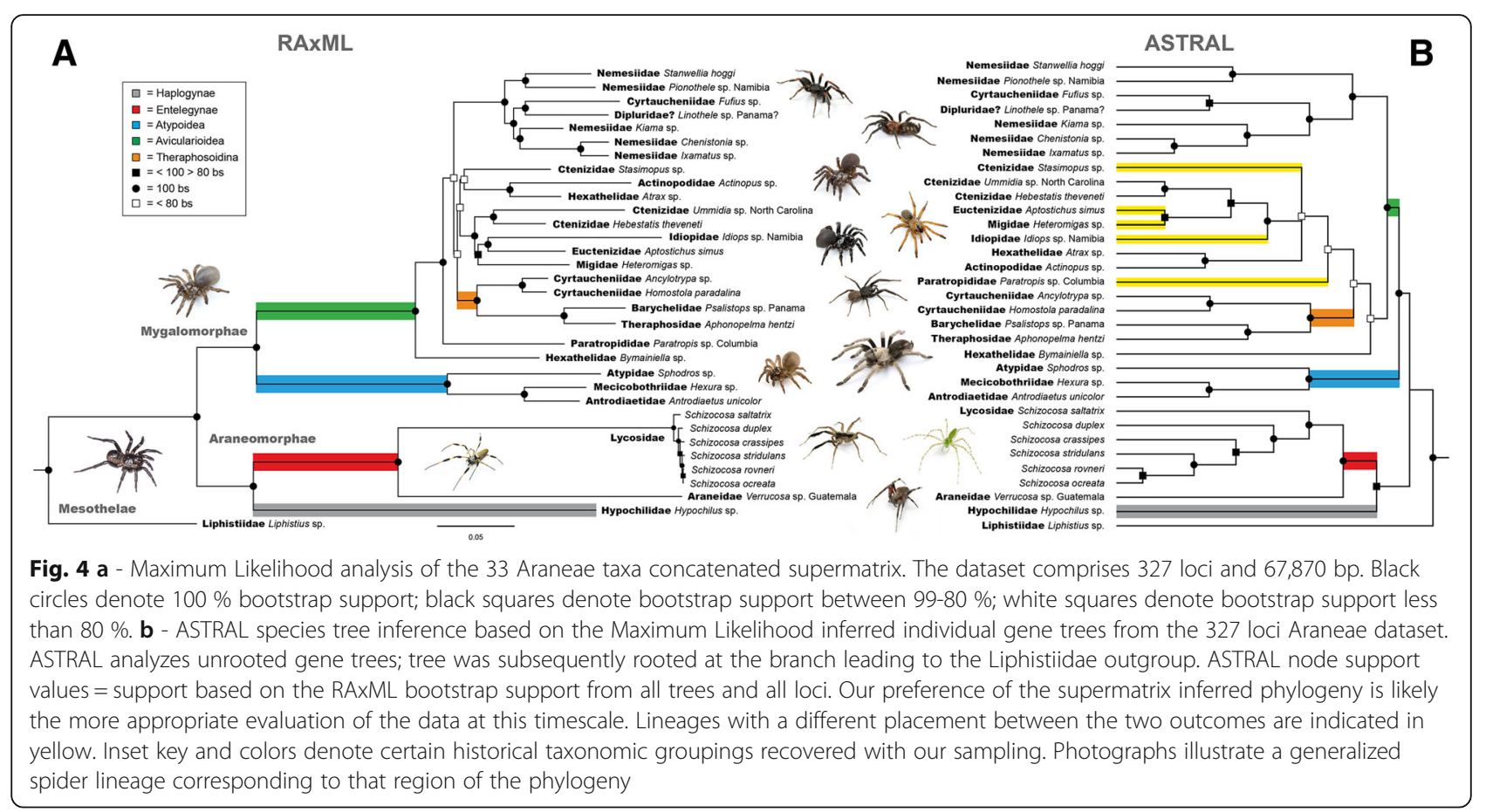

provide evidence of at least three polyphyletic families (Ctenizidae, Cyrtaucheniidae, and Hexathelidae), and indicate the Ctenizidae are polyphyletic with respect to the placement of the genus Stasimopus.

The low support within certain medium-depth nodes and our limited sampling precludes a definitive understanding of mygalomorph families (e.g., the Crassitarsae and whether the Nemesiidae are sister to the Theraphosoidina, as well as the placement of the families Dipluridae and Microstigmatidae - both critically important to understanding mygalomorph evolution). While increasing taxon sampling will likely increase node support for most of the tree [77], given the evolutionary depth of this clade, it is more likely that removing saturated sites from future datasets will aid in improving support values, especially in the middle to deep regions of the phylogeny.

\section{Euctenizidae}

The 25 sequenced taxa include family and inter-generic relationships spanning the mygalomorph family Euctenizidae (Table 1). Following hybrid enrichment, sequencing, and implementation of the AHE bioinformatics pipeline, a dataset of 403 loci comprising 133,614 bp was selected for phylogenetic inference. The dataset contains 42,046 variable sites, 22,548 informative sites, and $12.5 \%$ total missing characters. Of the $403 \mathrm{loci}$, an average of 24 taxa were represented in each locus. The length of the individual alignments ranged between $117 \mathrm{bp}$ and $1817 \mathrm{bp}$, with a mean of $331 \mathrm{bp}$, and the number of PICs range from 1-298 (Figs. 2 \& 3b). The family Idiopidae, a putative closely related sister lineage based on preliminary data and Bond et al. [17], was used to root the phylogeny, a result not confirmed when more taxa were included (see above). The supermatrix and species tree analyses produced virtually identical topologies within the Euctenizidae, with high bootstrap support among nearly all nodes, and producing strongly supported generic relationships within the family and species relationships within the genus Aptostichus (Fig. 5). All deep and intermediate node support was high ( $>80 \mathrm{bs}$ ). As discussed above, due to methodological restrictions at this time (see $[29,69,74,75]$ ), the species tree inference is likely the more appropriate evaluation of the data at this timescale (Fig. 5a).

Comparison of the phylogenies herein with the Aptostichus morphological phylogeny proposed by Bond [78] identifies disagreement with respect to species groups and species-level relationships. Additionally, relationships between the other euctenizid genera included in Bond [78] are drastically different (Neoapachella,(Eucteniza,(Entychides,(Promyrmekiaphila,(Myrmekiaphila,(Apomastus,Aptostichus)))))), when compared to our inferred relationships (Fig. 5a). In Bond [78], Myrmekiaphila is hypothesized as being closely related to Aptostichus, significantly different from our results. Within Aptostichus, the non-monophyly of the Hesperus group and the Atomarius group is strongly supported (Fig. 5). The Hesperus group is rendered polyphyletic due to the removal of $A$. hedinorum and placing it as the sister lineage to all other sampled Aptostichus, except for the basal $A$. simus lineage. The tree also identifies a paraphyletic Atomarius group, with the placement of a monophyletic clade from the morphological Hesperus group inside the Atomarius clade (Fig. 5). 


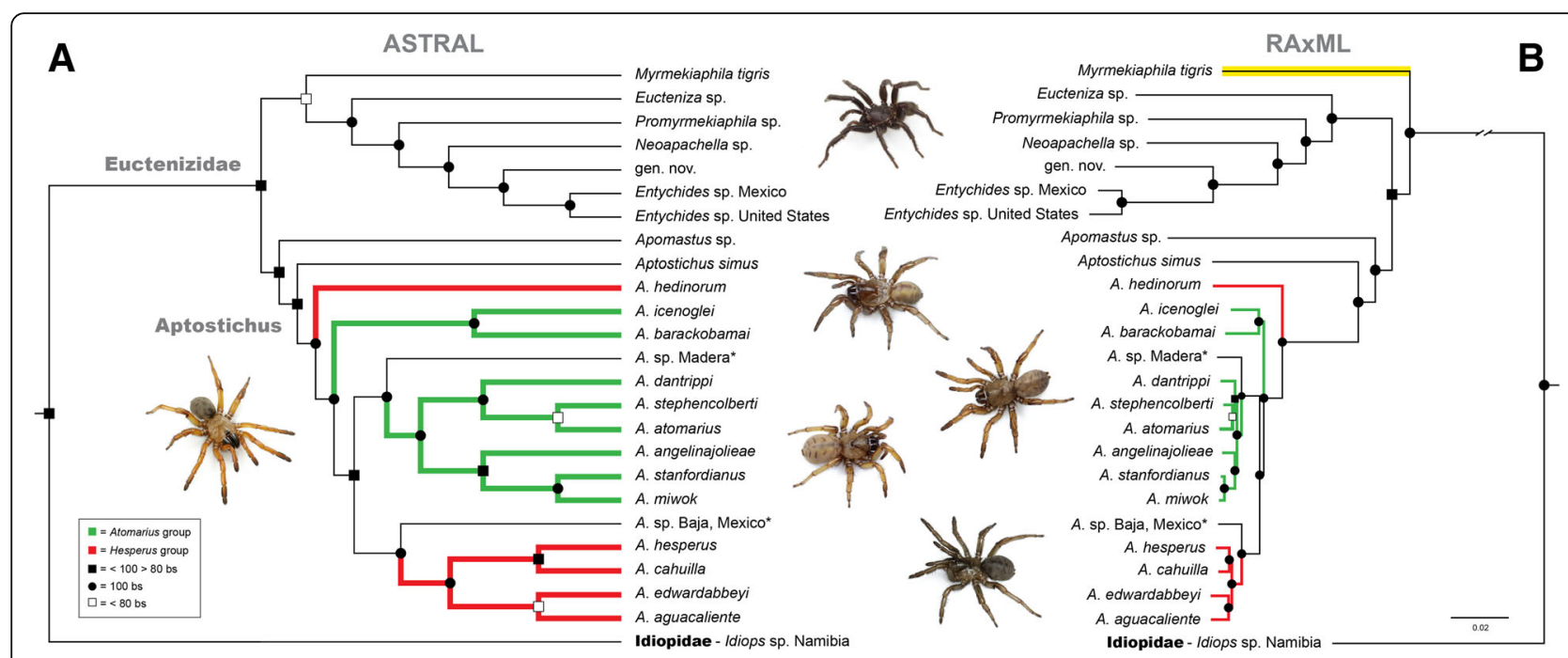

Fig. 5 a - ASTRAL species tree inference based on the Maximum Likelihood inferred individual gene trees from the 25 taxa Euctenizidae family/ genus level dataset, comprising 403 loci and 133,614 bp. ASTRAL analyzes unrooted gene trees; tree was subsequently rooted at the branch leading to the Idiopidae outgroup. ASTRAL node support values = support based on the RAxML bootstrap support from all trees and all loci. b - Maximum Likelihood analysis of the Euctenizidae concatenated supermatrix. Black circles denote $100 \%$ bootstrap support; black squares denote bootstrap support between 99-80\%; white squares denote bootstrap support less than $80 \%$. The species tree inference is likely the more appropriate evaluation of the data at this timescale. Inset key and colors denote certain historical taxonomic groupings recovered with our sampling. The non-monophyly of the morphological Atomarius and Hesperus species groups is identified. Novel taxa are denoted by an asterisk. Photographs illustrate a generalized spider lineage corresponding to that region of the phylogeny

\section{Aphonopelma}

Following hybrid enrichment, sequencing, and implementation of the AHE bioinformatics pipeline, a dataset of 581 loci comprising 334,436 bp for 83 OTUs was selected for phylogenetic inference. The dataset contains 79,912 variable sites, 44,342 informative sites, and $7.3 \%$ total missing characters. Of the 581 loci, an average of 80 taxa were represented in each locus. The length of the individual alignments ranged between $156 \mathrm{bp}$ and $2146 \mathrm{bp}$, with a mean of $575 \mathrm{bp}$, and the number of PICs range from 11-317 (Figs. 2 \& 3c). To evaluate the monophyly of the genus, Central American taxa (Aphonopelma belindae (APH_3001), A. sp. burica (APH_3012), Sericopelma sp. (APH_3004), Stichoplastoris sp. (AUMS_10968)), a putative novel genus of miniature tarantula from Mexico (APH_3021), and a genus from the Caribbean (Cyrtopholis portoricae, APH_3056) were included. Both analyses indicate that Aphonopelma, as presently defined, is not monophyletic, with all other genera (i.e., morphologically divergent) sampled rendering the genus paraphyletic. As in Euctenizidae, the supermatrix and species tree estimation produced virtually identical topologies with high bootstrap support throughout (Fig. 6). The phylogeny inferred through the species tree approach is likely the more appropriate evaluation of the data at this timescale, and thus the species tree was our preferred topology (Fig. 6a). Lineages with a different placement between the two outcomes are indicated in yellow on the phylogeny (Fig. 6b).
There are six major morphologically distinct lineages identified in the phylogeny, as defined by Hamilton et al. [79]: the Hentzi species group, the Moderatum species group, the Marxi species group (from the Madrean Archipelago/Sky Islands region of southeastern Arizona and southwestern New Mexico), the Iodius species group, a group of miniature Aphonopelma (the Paloma species group), and the Steindachneri species group. In the species tree analysis, all of these major lineages, except the Marxi species group (59 bs), are highly supported (100 bs) and monophyletic (Fig. 6a). All 28 of the recently revised species in Hamilton et al. [79] are strongly supported as representing genealogically exclusive, independently evolving lineages, with one exception, Aphonopelma iodius. In the species tree analysis, all species are monophyletic and genealogically exclusive, with high support ( $\geq 90 \mathrm{bs}$ ), except $A$. iodius - paraphyletic with respect to $A$. johnnycashi, itself a highly supported monophyletic clade that is morphologically and geographically distinct. Though monophyletic in the supermatrix analysis with high support (95 bs), A. iodius is a known problematic species (see [79]) that has likely experienced high levels of gene flow between populations and rapid expansion and growth in the relative recent geologic past. The only major difference in topology seen across both analyses corresponds to the placement of $A$. marxi and $A$. vorhiesi. The supermatrix dataset strongly supports (100 bs) the placement of $A$. marxi as a member of the Marxi species group, but 


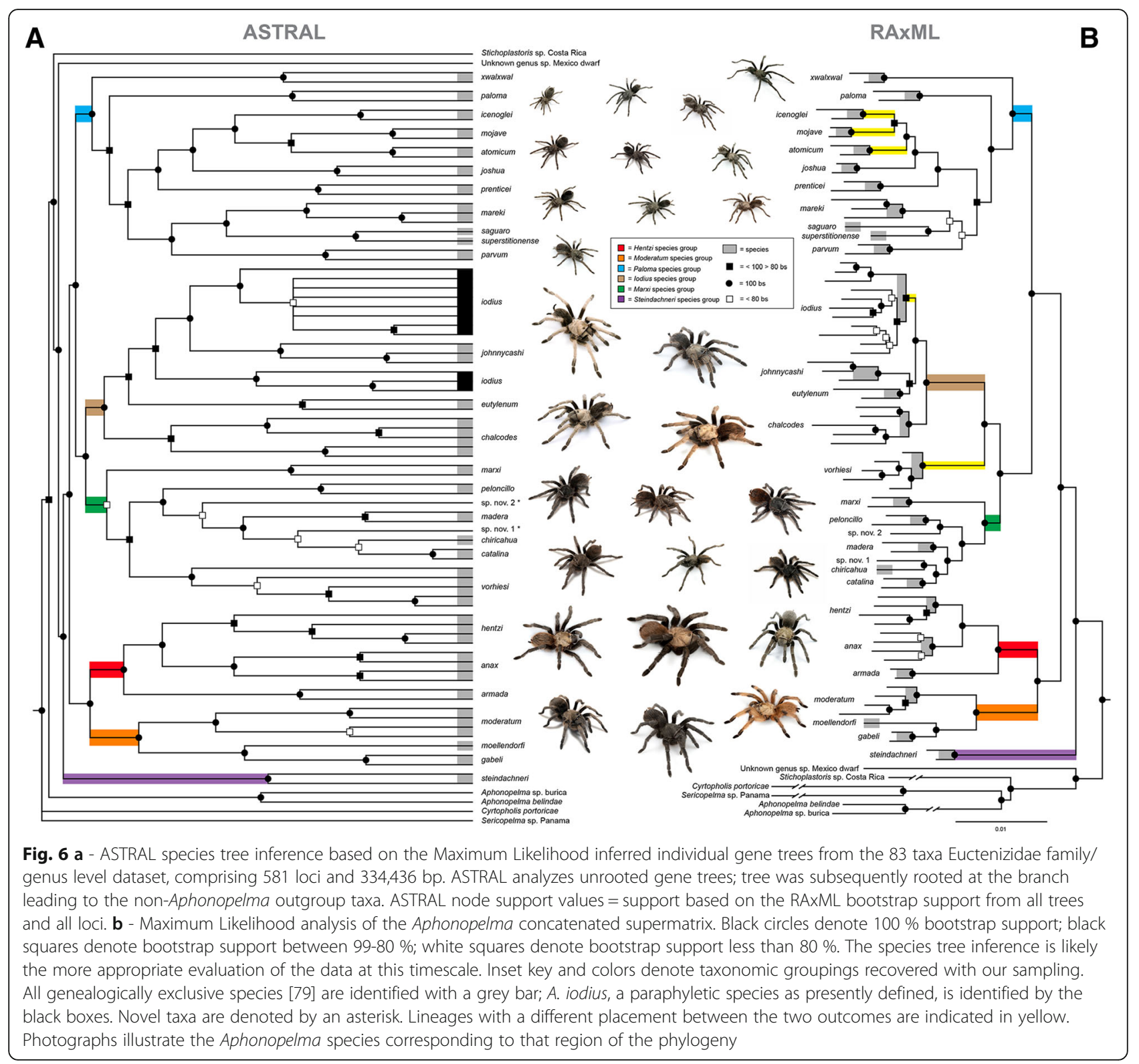

excludes $A$. vorhiesi, which is placed as the sister lineage (100 bs) to the Iodius species group - a grouping similarly seen in the $\mathrm{CO} 1$ data (see Hamilton et al. $[58,79]$ ), and likely caused by mitochondrial introgression. In the $C O 1$ dataset, a sister relationship is inferred between $A$. vorhiesi and $A$. chalcodes in the face of radically divergent morphology and phenotype. Aphonopelma vorhiesi is a medium size black spider and $A$. chalcodes is large bodied with contrasting light and dark. Nothing in our knowledge of these two species suggests this sister relationship to be accurate (see [79]), but we do know that these two species are sympatric throughout much of SE Arizona. In comparison, the species tree places both $A$. marxi and A. vorhiesi within the Sky Islands species group. Additionally, this outcome highlights the dangers of using a concatenated supermatrix approach to infer phylogenetic relationships at the species level, particularly if there are nodes that fall within the anomaly zone [29].

Lastly, when we compare the mitochondrial (CO1) species outlined by Hamilton et al. [58] to the AHE species tree, a number of these previously putative species hypotheses correspond to lineages that were considered "cryptic species", yet when viewed in the light of the AHE data are no longer distinct (e.g., sp. nov. A - A. vorhiesi cryptic, sp. nov. B - A. vorhiesi cryptic, sp. nov. F A. peloncillo cryptic, sp. moderatum nov. sp. hentzi nov. 1). These findings illuminate how deep mitochondrial divergence and introgression have obscured our understanding of the true evolutionary history of these lineages - a phenomenon seen more often now as 
nuclear loci are more easily gathered (see [80]). This outcome is not surprising given the large number of papers showing how the use of a single locus, like mtDNA data, to delimit species can be misleading (e.g., [81, 82]).

\section{Conclusions}

By specifically targeting 585 phylogenetically informative loci across the Order Araneae, the AHE Spider Probe Kit provides an order of magnitude larger dataset than any previously generated by traditional targeted sequencing approaches. Anchored Hybrid Enrichment delivers phylogenetic utility at both deep and shallow taxonomic depths thereby providing a much needed set of molecular markers that can be used to address evolutionary questions at multiple hierarchical levels. Though our research is not the first to implement this type of targeted sequencing in invertebrates (e.g., studies in divergent groups throughout Class Insecta are beginning to be published (Diptera - [83]; Hymenoptera - [84, 85]; and Lepidoptera - Breinholt and Kawahara [91])), it is the first implementation of this methodology in Class Arachnida. While the initial cost for the development of the Spider Probe Kit was high (owing primarily to the large genome sizes of mygalomorphs and the subsequent need for deeper sequencing coverage for the genome scans), costs for the kit, extraction, library preparation, and sequencing continue to decrease, making this approach suitable for large-scale projects or collaborations between researchers. Future users will find that the amount and quality of data recovered is remarkable and the cost per specimen low (for detailed cost information see 19, 30, and www.anchoredphylogeny.com).

We know the use of AHE, or any phylogenomic approach, is not a panacea and that certain nodes in the Tree of Life may be beyond resolution [86-88]. The development of the Spider Probe Kit holds great promise for gathering the types and quantities of molecular data needed to understand the evolution of spiders, including a mechanism whereby researchers can confidently and effectively use the same loci, allowing for future metaanalyses to better understand the spider Tree of Life. Not only will this and future datasets be informative to our understanding of spider evolution, the deep arthropod-wide markers included in the probe design allows the Order Araneae to be included in future research that seeks to understand the deeper Arachnida, Chelicerata, and Arthropoda Tree of Life relationships.

Finally, it is important to note that a major benefit of this approach allows specimens from natural history collections to be sequenced, provided DNA can be retrieved. All of our test specimens (see Methods and Table 1) captured a moderate to exceptional number of loci. This finding opens many new avenues of investigation by allowing for the placement of extinct taxa into a phylogeny, or examining evolutionary response over time to an environmental pressure. Although our initial probe kit development was biased towards mygalomorphs, due to the inclusion of a large number mygalomorph transcriptomes and the two mygalomorph genome scans, a new version of the Spider Probe Kit (v.2) has recently been developed and includes increased genomic scans of araneomorph taxa as well as araneomorph transcriptomes in order to allow the v. 2 capture probe set to consistently recover a higher number of loci across all spider taxa under investigation.

\section{Additional files}

Additional file 1: Table S1. The 13 "usual suspect" molecular markers used throughout spiders, previous to the usage of next-generation sequencing for phylogenomics. nuDNA = genomic DNA, mtDNA = mitochondrial DNA (CSV 112 bytes)

Additional file 2: Table S2. Table A - A full list of the species and their higher taxonomy; Table B - Details of the 962 preliminary targets; Table C - Arachnid genomic data used in development of the Anchored Hybrid Enrichment Spider Probe Kit v.1. (XLSX 128 kb)

Additional file 3: Table S3. GenomeSequencingSummary. Summary of the genomic reads obtained for Aliatypus and Aphonopelma. (XLSX $50 \mathrm{~kb}$ )

Additional file 4: Table S4. Ara1_Key_withReplicates. Number of Agilent Sure-Select enrichment kit probes per locus in the Anchored Hybrid Enrichment Spider Probe Kit v.1. (XLSX 1027 kb)

Additional file 5: Table S5. P0073_AssemblySummary. Summary of the sequence data collected and resulting assemblies. (XLSX 80 kb)

\section{Acknowledgements}

We are indebted to all those who donated specimens (Marshal Hedin, Ingi Agnarsson, Charles Ray, Rebecca Godwin, Nicole Garrison, Charles Stephen, Cor Vink, Matjaž Kuntner, and many, many others). Specimens collected from National Park Service lands were permitted by: DEVA-2010-SCI-0012 (Death Valley National Park); JOTR-2008-SCI-0017 and JOTR-2010-SCI-0015 (Joshua Tree National Park); LAME-2010-SCI-0008 (Lake Mead NRA); MOJA-2010-SCl0032 (Mojave National Preserve); SAGU-2010-SCI-0009; Saguaro National Park; ZION-2010-SCI-0014 (Zion National Park). Specimens collected from California and California State Parks lands were permitted by Dept. of Fish and Game scientific collecting permit \#802021-05 and Dept. of Parks and Recreation \#9-2195(08||12010). Specimens collected from state land in Texas and Alabama were done so with permission from their respective Parks \& Wildlife departments. Specimens collected from private lands with permission from the landowner. We are grateful to Michelle Kortyna, Hannah Ralicki, and Alyssa Bigelow for contributing to data collection, and to Roger Mercer and Yanming Yang for assistance with sequencing at Florida State University's Translational Science Facility in the College of Medicine. We are also thankful for the thoughtful reviews of the anonymous reviewers of this manuscript.

\section{Funding}

Funding was provided by the National Science Foundation (DEB-0841610 to JEB; Doctoral Dissertation Improvement Grant - DEB1311494 to (AH); Auburn University Department of Biological Sciences and College of Sciences and Mathematics (JEB); an Auburn University Cellular and Molecular Biosciences Peaks of Excellence Research Fellowship (CAH). This is contribution \#0738 of the Auburn University Museum of Natural History. Funding was provided by the National Science Foundation through awards to ARL and EML, (NSF IIP-1313554), and to EML (NSF DEB-1120516).

\section{Availability of data and materials}

The Illumina sequencing reads and data sets supporting the results and conclusions of this article are available in the Dryad data repository, http://datadryad.org, doi:10.5061/dryad.5027d, and included within the article and its additional files. 


\section{Authors' contributions}

$C A H, A R L, E M L$, and JEB conceived of the study. CAH, ARL, EML, and JEB provided reagents and collected data. CAH and ARL analyzed the data. CAH and ARL wrote the manuscript. CAH, ARL, EML, and JEB provided comments on early drafts of the manuscript. All authors read, revised, and approved the final manuscript. CAH, ARL, EML, and JEB funded the study. CAH and ARL equally contributed to this project.

\section{Competing interests}

The authors declare that they have no competing interests.

\section{Consent for publication}

Not applicable.

\section{Ethics approval and consent to participate}

Not applicable.

\section{Author details}

'Department of Biological Sciences, Auburn University \& Auburn University Museum of Natural History, Auburn, AL, USA. ${ }^{2}$ Department of Scientific Computing, Florida State University, Tallahassee, FL, USA. ${ }^{3}$ Department of Biological Science, Florida State University, Tallahassee, FL, USA.

\section{Received: 4 June 2016 Accepted: 28 September 2016} Published online: 13 October 2016

\section{References}

1. World Spider Catalog. 2016. Natural History Museum Bern, online at http:// wsc.nmbe.ch, version 17, Accessed 02/2016.

2. Agnarsson I, Coddington JA, Kuntner M. Systematics. In: Spider Research in the 21st Century Progress in the study of spider diversity and evolution. Manchester: Siri Scientific Press; 2013. p. 58-111.

3. Bond JE, Garrison NL, Hamilton CA, Godwin RL, Hedin M, Agnarsson I. Phylogenomics resolves a spider backbone phylogeny and rejects a prevailing paradigm for Orb Web evolution. Curr Biol. 2014;24:1765-71.

4. Garrison NL, Rodriguez J, Agnarsson I, Coddington JA, Griswold CE, Hamilton CA, Hedin M, Kocot KM, Ledford JM, Bond JE. Spider phylogenomics: untangling the spider tree of life. Peer J. 2016;4:e1719. doi: 10.7717/peerj.1719.

5. Platnick NI, Raven RJ. Spider systematics: past and future. Zootaxa. 2013; 3683:595-600

6. Coddington J, Levi H. Systematics and evolution of spiders (Araneae). Annu Rev Ecol Syst. 1991;22:565-92.

7. Coddington J. 2005. Phylogeny and classification of spiders. In: Spiders of North America: an identification manual. (Eds. Ubick D, Paquin P, Cushing PE, Roth V) American Arachnological Society. 18-24.

8. Ramírez MJ. The morphology and phylogeny of dionychan spiders (Araneae: Araneomorphae). Bull Am Mus Nat Hist. 2014;390:1-374.

9. Hormiga G, Griswold CE. Systematics, phylogeny, and evolution of orbweaving spiders. Annu Rev Entomol. 2014;59:487-512.

10. Gillespie RG, Croom HB, Palumbi SR. Multiple origins of a spider radiation in Hawaii. PNAS. 1994;91:2290-4.

11. Hedin M. Molecular phylogenetics at the population/species interface in cave spiders of the southern Appalachians (Araneae: Nesticidae: Nesticus). Mol Biol Evol. 1997;14:309-24.

12. Agnarsson I, Maddison W, Aviles L. The phylogeny of the social Anelosimus spiders (Araneae: Theridiidae) inferred from six molecular loci and morphology. Mol Phylogenet Evol. 2007:43:833-51.

13. Ayoub N, Garb J, Hedin M, Hayashi C. Utility of the nuclear protein-coding gene, elongation factor-1 gamma (EF-1 [gamma]), for spider systematics, emphasizing family level relationships of tarantulas and their kin (Araneae: Mygalomorphae). Mol Phylogenet Evol. 2007;42:394-409.

14. Vink CJ, Hedin M, Bodner MR, Maddison WP, Hayashi CY, Garb JE. Actin 5C, a promising nuclear gene for spider phylogenetics. Molecular Phylogenetics \& Evolution. 2008:48:377-82.

15. Blackledge TA, Scharff N, Coddington JA, Szüts T, Wenzel JW, Hayashi CY, Agnarsson I. Reconstructing web evolution and spider diversification in the molecular era. PNAS. 2009;106:5229-34.

16. Hamilton CA, Formanowicz DR, Bond JE. Species delimitation and phylogeography of Aphonopelma hentzi (Araneae, Mygalomorphae,
Theraphosidae): cryptic diversity in North American tarantulas. PLoS One. 2011:6:e26207.

17. Bond JE, Hendrixson BE, Hamilton CA, Hedin M. A reconsideration of the classification of the spider infraorder Mygalomorphae (Arachnida: Araneae) based on three nuclear genes and morphology. PLoS One. 2012;7:e38753.

18. Satler JD, Carstens BC, Hedin M. Multilocus species delimitation in a complex of morphologically conserved trapdoor spiders (Mygalomorphae, Antrodiaetidae, Aliatypus). Syst Biol. 2013;62:805-23.

19. Dimitrov D, Benavides LR, Arnedo MA, Giribet G, Griswold CE, Scharff N, Hormiga G. Rounding up the usual suspects: a standard target-gene approach for resolving the interfamilial phylogenetic relationships of ecribellate orb-weaving spiders with a new family-rank classification (Araneae, Araneoidea). Cladistics. 2016. in press.

20. Lemmon EM, Lemmon AR. High-throughput genomic data in systematics and phylogenetics. Annual Review Of Ecology Evolution And Systematics. 2013;44:99-121.

21. Lemmon AR, Brown JM, Stanger-Hall K, Lemmon EM. The effect of ambiguous data on phylogenetic estimates obtained by maximum likelihood and Bayesian inference. Syst Biol. 2009:58:130-45.

22. Roure B, Baurain D, Philippe H. Impact of missing data on phylogenies inferred from empirical phylogenomic data sets. Mol Biol Evol. 2012;30:197214.

23. Dell'Ampio E, Meusemann K, Szucsich NU, Peters RS, Meyer B, Borner J, Petersen M, Aberer AJ, Stamatakis A, Walzl M. Decisive data sets in phylogenomics: lessons from studies on the phylogenetic relationships of primarily wingless insects. Mol Biol Evol. 2014;31:239-49.

24. Xia X. Phylogenetic Bias in the Likelihood Method Caused by Missing Data Coupled with Among-Site Rate Variation: An Analytical Approach. In: Mitra B, Yi P, Jianxin W, editors. Bioinformatics Research and Applications, vol. Ch. 2. 2014. p. 12-23.

25. Brandley MC, Bragg JG, Singhal S, Chapple DG, Jennings CK, Lemmon AR, Moriarty Lemmon $\mathrm{E}$, Thompson MB, Mortiz C. Evaluating the performance of anchored hybrid enrichment at the tips of the tree of life: a phylogenetic analysis of Australian Eugongylus group scincid lizards. BMC Evol Biol. 2015; 15(62):1-14.

26. Posada D, Crandall KA. The effect of recombination on the accuracy of phylogeny estimation. J Mol Evol. 2002;54:396-402.

27. Posada D, Crandall KA, Holmes EC. Recombination in evolutionary genomics. Annu Rev Genet. 2002;36:75-97.

28. Sanggaard KW, Bechsgaard JS, Fang X, Duan J, Dyrlund TF, Gupta V, Jiang X, Cheng L, Fan D, Feng Y, Han L, Huang Z, Funch P, Enghild JJ, Schauser L, Andersen SU, Villesen P, Schierup MH, Bilde T, Wang J. Spider genomes provide insight into composition and evolution of venom and silk. Nat Commun. 2014:5:1-11.

29. Rannala B, Yang Z. Phylogenetic inference using whole genomes. Annu Rev Genomics Hum Genet. 2008:9:217-31.

30. Edwards SV, Xi Z, Janke A, Faircloth BC, McCormack JE, Glenn TC, Zhong B, Wu S, Lemmon EM, Lemmon AR, Leaché AD. Implementing and testing the multispecies coalescent model: a valuable paradigm for phylogenomics. Mol Phylogenet Evol. 2016;94:447-62.

31. Lemmon AR, Emme SA, Lemmon EM. Anchored Hybrid Enrichment for massively high-throughput phylogenomics. Syst Biol. 2012;61:717-26.

32. Faircloth BC, McCormack JE, Crawford NG, Harvey MG, Brumfield RT, Glenn TC. Ultraconserved elements anchor thousands of genetic markers spanning multiple evolutionary timescales. Syst Biol. 2012;61:717-26.

33. Li C, Hofreiter M, Straube N, Corrigan S. Capturing protein-coding genes across highly divergent species. Biotechniques. 2013;54:321-6.

34. Crawford NG, Faircloth BC, McCormack JE, Brumfield RT, Winker K, Glenn TC. More than 1000 ultraconserved elements provide evidence that turtles are the sister group of archosaurs. Biol Lett. 2012;8:783-6.

35. McCormack JE, Faircloth BC, Crawford NG, Adair Gowaty P, Brumfield RT, Glenn TC. Ultraconserved elements are novel phylogenomic markers that resolve placental mammal phylogeny when combined with species-tree analysis. Genome Res. 2012;22:746-54.

36. Faircloth BC, Sorenson L, Santini F, Alfaro ME. A phylogenomic perspective on the radiation of Ray-finned fishes based upon targeted sequencing of Ultraconserved Elements (UCEs). PLoS One. 2013:8:e65923.

37. McCormack JE, Harvey MG, Faircloth BC, Crawford NG, Glenn TC, Brumfield RT. A phylogeny of birds based on over 1,500 loci collected by target enrichment and high-throughput sequencing. PLoS One. 2013;8:e54848. 
38. Leaché AD, Wagner P, Linkem CW, Böhme W, Papenfuss TJ, Chong RA, Lavin BR, Bauer AM, Nielsen SV, Greenbaum E, Rödel M-O, Schmitz A, LeBreton M, Ineich I, Chirio L, Ofori-Boateng C, Eniang EA, El Din SB, Lemmon AR, Burbrink FT. A hybrid phylogenetic-phylogenomic approach for species tree estimation in African Agama lizards with applications to biogeography, character evolution, and diversification. Molecular Phylogenetics \& Evolution. 2014;79:215-30.

39. Pyron RA, Hendry CR, Chou VM, Lemmon EM. Effectiveness of phylogenomic data and coalescent species-tree methods for resolving difficult nodes in the phylogeny of advanced snakes (Serpentes: Caenophidia). Molecular Phylogenetics \& Evolution. 2014;81:221-31.

40. Crawford NG, Parham JF, Sellas AB, Faircloth BC, Glenn TC, Papenfuss TJ, Henderson JB, Hansen MH, Simison BW. A phylogenomic analysis of turtles. Mol Phylogenet Evol. 2015;83:250-7.

41. Eytan Rl, Evans BR, Dornburg A, Lemmon AR, Lemmon EM, Wainwright PC, Near TJ. Are 100 enough? Inferring acanthomorph teleost phylogeny using anchored hybrid enrichment. BMC Evol Biol. 2015;15(113):1-20.

42. Pyron RA, Hsieh FW, Lemmon AR, Lemmon EM, Hendry CR. Integrating phylogenomic and morphological data to assess candidate speciesdelimitation models in brown and red-bellied snakes (Storeria). Zool J Linnean Soc. 2016;177:937-48.

43. Král J, Kořínková T, Krkavcová L, Musilová J, Forman M, Ávila Herrera IM, Haddad CR, Vítková M, Henriques S, Palacios Vargas JG, Hedin M. Evolution of karyotype, sex chromosomes, and meiosis in mygalomorph spiders (Araneae: Mygalomorphae). Biological Journal of the Linnaean Society. 2013;109:377-408.

44. Knowles LL, Kubatko LS. Estimating Species Trees - Practical and Theoretical Aspects. Hoboken: Wiley \& Sons; 2010. p. 215.

45. Leaché $A D$, Rannala B. The accuracy of species tree estimation under simulation: a comparison of methods. Syst Biol. 2011;60:126-37.

46. Liu L, Yu L. Estimating species trees from unrooted gene trees. Syst Biol. 2011;60:661-7.

47. Maddison W, Knowles L. Inferring phylogeny despite incomplete lineage sorting. Syst Biol. 2006;55:21-30.

48. Edwards S, Liu L, Pearl D. High-resolution species trees without concatenation. PNAS. 2007;104:5936-41.

49. Huang $H, H e$ Q, Kubatko LS, Knowles LL. Sources of error inherent in species-tree estimation: impact of mutational and coalescent effects on accuracy and implications for choosing among different methods. Syst Biol. 2010:59:573-83.

50. Niehuis O, Hartig G, Grath S, Pohl H, Lehmann J, Tafer H, Donath A, Krauss V, Eisenhardt C, Hertel J, Petersen M, Mayer C, Meusemann K, Peters RS, Stadler PF, Beutel RG, Bornberg-Bauer E, McKenna DD, Misof B. Genomic and morphological evidence converge to resolve the enigma of Strepsiptera. Curr Biol. 2012a;22(14):1309-13. http://dx.doi.org/10.1016/j.cub. 2012.05.018

51. Niehuis O, Hartig G, Grath S, Pohl H, Lehmann J, Tafer H, Donath A, Krauss V, Eisenhardt C, Hertel J, Petersen M, Mayer C, Meusemann K, Peters RS, Stadler PF, Beutel RG, Bornberg-Bauer E, McKenna DD, Misof B. Data from: genomic and morphological evidence converge to resolve the enigma of strepsiptera. 2012b. Dryad Digital Repository, http://dx.doi.org/10.5061/ dryad.ts058.2.

52. Misof B, Liu S, Meusemann K, et al. Phylogenomics resolves the timing and pattern of insect evolution. Science. 2014;346:763-7.

53. Hamilton CA, Lemmon AR, Moriarty Lemmon E, Bond JE. Data from: Expanding anchored hybrid enrichment to resolve both deep and shallow relationships within the spider tree of life. Dryad Digital Repository; 2016. doi:10.5061/dryad.5027d.

54. Katoh K, Standley DM. MAFFT multiple sequence alignment software version 7: improvements in performance and usability. Mol Biol Evol. 2013;30:772-80

55. i5K Consortium. The i5K initiative: advancing arthropod genomics for knowledge, human health, agriculture, and the environment. J Hered. 2013; 104:595-600.

56. Bashiardes S, Veile R, Helms C, Mardis ER, Bowcock LM. Direct genomic selection. Nat Methods. 2005;2(1):63-9.

57. Fu Y, Springer NM, Gerhardt DJ, Ying K, Yeh CT, Wu W, Swanson-Wagner R, D'Ascenzo M, Millard T, Freeberg L, Aoyama N, Kitzman J, Burgess D, Richmond T, Albert TJ, Barbazuk WB, Jeddeloh JA, Schnable PS. Repeat subtraction-mediated sequence capture from a complex genome. Plant J. 2010;62:898-909.
58. Mamanova L, Coffey AJ, Scott CE, Kozarewa I, Turner EH, Kumar A, Howard E, Shendure J, Turner DJ. Target-enrichment strategies for next-generation sequencing. Nat Methods. 2010;7(2):111-8.

59. Gregory TR. Animal Genome Size Database. 2015. http://www.genomesize.com.

60. Hamilton CA, Hendrixson BE, Brewer MS, Bond JE. An evaluation of sampling effects on multiple DNA barcoding methods leads to an integrative approach for delimiting species: a case study of the North American tarantula genus Aphonopelma (Araneae, Mygalomorphae, Theraphosidae). Mol Phylogenet Evol. 2014;71:79-93.

61. Prum RO, Berv JS, Dornburg A, Field DJ, Townsend JP, Moriarty LE, Lemmon AR. A comprehensive phylogeny of birds (Aves) using targeted nextgeneration DNA sequencing. Nature. 2015;526:569-73.

62. Meyer M, Kircher M. Illumina sequencing library preparation for highly multiplexed target capture and sequencing. Cold Spring Harbor Protocols. 2010;6:1-10.

63. Rokyta DR, Lemmon AR, Margres MJ, Aronow K. The venom-gland transcriptome of the eastern diamondback rattlesnake (Crotalus adamanteus). BMC Genomics. 2012;13:1-23.

64. Kriventseva EV, Tegenfeldt F, Petty T, Waterhouse RM, Simão FA, Pozdnyakov IA, loannidis P, Zdobnov EM. OrthoDB v8: update of the hierarchical catalog of orthologs and the underlying free software. Nucleic Acids Res. 2015;43:D250-6.

65. Stamatakis A. RAxML-VI-HPC: maximum likelihood-based phylogenetic analyses with thousands of taxa and mixed models. Bioinformatics. 2006;22:2688-90.

66. Stamatakis A, Aberer AJ. Novel parallelization schemes for large-scale likelihood-based phylogenetic inference. In: 2013 IEEE 27th International Symposium on Parallel \& Distributed Processing. 2013. p. 1195-204.

67. Darriba D, Taboada GL, Doallo R, Posada D. jModelTest 2: more models, new heuristics and parallel computing. Nat Methods. 2012;9:772.

68. Maddison W. Gene trees in species trees. Syst Biol. 1997;46:523-36.

69. Mirarab S, Warnow T. ASTRAL-II: coalescent-based species tree estimation with many hundreds of taxa and thousands of genes. Bioinformatics. 2015;31:144-52

70. Reaz R, Bayzid MS, Rahman MS. Accurate phylogenetic tree reconstruction from quartets: a heuristic approach. PLoS One. 2014;9:e104008.

71. Mirarab S, Reaz R, Bayzid MS, Zimmerman T, Swenson MS, Warnow T. ASTRAL: genome-scale coalescent-based species tree estimation. Bioinformatics. 2014;30:i541-8.

72. Degnan $\mathrm{JH}$, Rosenberg NA. Discordance of species trees with their most likely gene trees. PLoS Genet. 2006;2(5):e68.

73. Liu L, Edwards SV. Phylogenetic analysis in the anomaly zone. Syst Biol. 2009:58(4):452-60.

74. Sayyari E, Mirarab S. Fast coalescent-based computation of local branch support from quartet frequencies. Mol Biol Evol. 2016;33(7):1654-68.

75. Kubatko LS, Degnan JH. Inconsistency of phylogenetic estimates from concatenated data under coalescence. Syst Biol. 2007;56:17-24.

76. Gatesy J, Springer MS. Phylogenetic analysis at deep timescales: unreliable gene trees, bypassed hidden support, and the coalescence/concatalescence conundrum. Mol Phylogenet Evol. 2014;80:231-66.

77. Springer MS, Gatesy J. The gene tree delusion. Mol Phylogenet Evol. 2016;94:1-33.

78. Doyle VP, Young RE, Naylor GJP, Brown JM. Can we identify genes with increased phylogenetic reliability? Syst Biol. 2015;64(5):824-37.

79. Philippe H, Brinkmann H, Lavrov DV, Littlewood DTJ, Manuel M, Wörheide G, Baurain D. Resolving difficult phylogenetic questions: Why more sequences Are Not enough. PLoS Biol. 2011;9:1-10.

80. Bond J. Phylogenetic treatment and taxonomic revision of the trapdoor spider genus Aptostichus Simon (Araneae, Mygalomorphae, Euctenizidae). ZooKeys. 2012;252:1-209.

81. Hamilton CA, Hendrixson BE, Bond JE. Taxonomic revision of the tarantula genus Aphonopelma Pocock, 1901 (Araneae, Mygalomorphae, Theraphosidae) within the United States. ZooKeys. 2016;560:1-340. doi:10.3897/zookeys.560.6264.

82. Toews DPL, Brelsford A. The biogeography of mitochondrial and nuclear discordance in animals. Mol Ecol. 2012;21:3907-30.

83. Rubinoff D, Cameron S, Will K. A genomic perspective on the shortcomings of mitochondrial DNA for "barcoding" identification. J Hered. 2006;97:581-94.

84. Petit R, Excoffier L. Gene flow and species delimitation. Trends In Ecology and Evolution. 2009;24:386-93.

85. Young AD, Lemmon AR, Skevington JH, Mengual X, Ståhls G, Reemer M, Jordaens K, Kelso S, Moriarty Lemmon E, Hauser M, De Meyer M, Misof B, 
Wiegmann B. Anchored enrichment dataset for true flies (order Diptera) reveals insights into the phylogeny of flower flies (family Syrphidae). BMC Evol Biol. 2016;16(143):1-13.

86. Blaimer BB, Brady SG, Schultz TR, Lloyd MW, Fisher BL, Ward PS.

Phylogenomic methods outperform traditional multi-locus approaches in resolving deep evolutionary history: a case study of formicine ants. BMC Evol Biol. 2015;15:271.

87. Faircloth BC, Branstetter MG, White ND, Brady SG. Target enrichment of ultraconserved elements from arthropods provides a genomic perspective on relationships among Hymenoptera. Mol Ecol Resour. 2015;15(3):489-501.

88. Breinholt JB, Lemmon AR, Lemmon E, Xiao L, Kawahara AY. Leveraging genomic data for studies on the megadiverse butterflies and moths: A novel anchored phylogenomic capture set. Systematic Biology; in press.

89. Delsuc F, Brinkmann H, Philippe H. Phylogenomics and the reconstruction of the tree of life. Nat Rev Genet. 2005:6:361-75.

90. Rokas A, Carroll SB. Bushes in the tree of life. PLoS Biol. 2006;4:1900-4.

91. Dunn CW, Hejnol A, Matus DQ, Pang K, Browne WE, Smith SA, Seaver E, Rouse GW, Obst M, Edgecombe GD, Sørensen MV, Haddock SHD, SchmidtRhaesa A, Okusu A, Møbjerg Kristensen R, Wheeler WC, Martindale MQ, Giribet G. Broad phylogenomic sampling improves resolution of the animal tree of life. Nature. 2008;452:745-9.

\section{Submit your next manuscript to BioMed Central and we will help you at every step:}

- We accept pre-submission inquiries

- Our selector tool helps you to find the most relevant journal

- We provide round the clock customer support

- Convenient online submission

- Thorough peer review

- Inclusion in PubMed and all major indexing services

- Maximum visibility for your research

Submit your manuscript at www.biomedcentral.com/submit 